Integrate the procedures of textual analysis of the poetic image Between rhetoric and stylistic

\author{
Dr. Hocine terrouche \\ Professor of Modern Arabic literature \\ Department of Arabic Language and Literature, \\ College of Arts and Languages, \\ University of Mohamed Lamine Dabbaghine, Setif 2, Algeria \\ terrouchehocine@yahoo.fr
}

DOI: $\underline{10.31973 / \text { aj.vli136.938 }}$

\begin{abstract}
:
The general aim of this intervention is to highlight the positive aspect of Arabic eloquence by comparing it to the methodical science that claims to be scientific and objective. At the same time, the personal and superficial rhetoric is accused by an important structural element of literary composition, the poetic image.

I chose the poetic picture because it is regarded in the eyes of rhetoric and stylistic as a linguistic composition based on the imagination, understanding and interpretation cannot go beyond the linguistic boundaries, which is an important way to combine the two sciences separated time and environment and brought together many procedural tools born in the hands of rhetoric and developed between the folds Stylistics.
\end{abstract}

Key words: cognitive integration - poetic image - rhetoric stylistic. 


\section{تكامل إجراءات التحليل التّصي للصّورة الشّعرية بين علم البلاغة وعلم الأسلوب

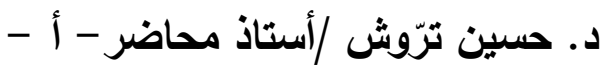

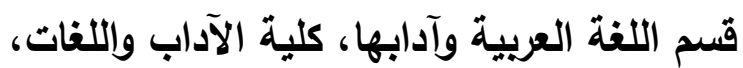 جامعة محمد لمين دبّاغين، سطيف ب الجزائر terrouchehocine@yahoo.fr}

(مُلَخََُّْ الَبَحث)

الهدف العام الذي تسعى هذه الدراسـة إلى تحقيقه هو إبراز الوجه الإيجابي للبلاغة

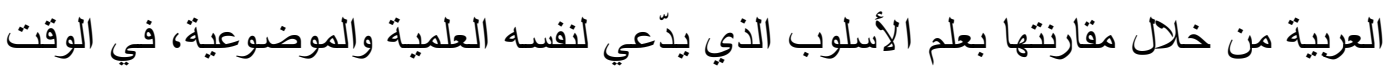

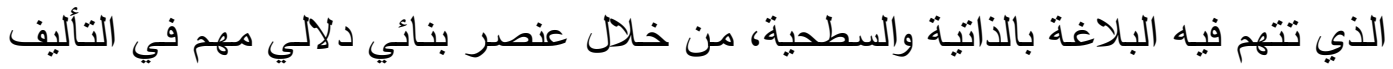

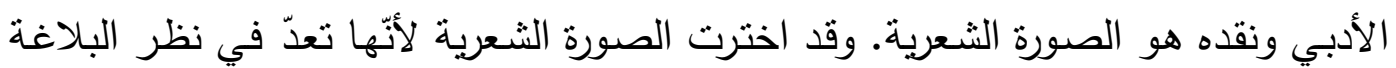

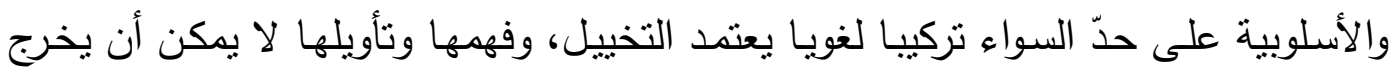
عن حدودها اللغوية، وهو منطلق مهم للجمع بين علمين فصل بينهما الزمن والبيئة وجمعت بينهما أدوات إجرائية كثيرة ولدت بين يدي البلاغة وتطوّرت بين ثنايا علم الأسلوب. ليتحدّد

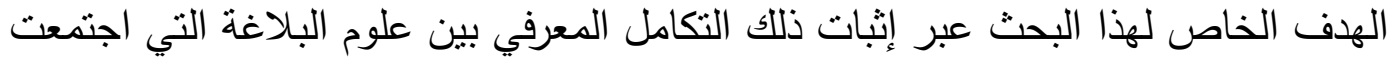

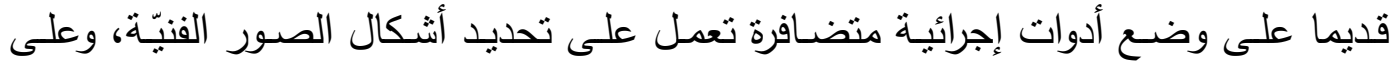
تفكيك بناها اللغوية، وعلم الأسلوب الذي أسّس الكثبر من جوانبه المعرفية وتطبيقاته النصيّة على هذا التزاث البلاغي العريق. الكلمات المفتاحية: التكامل المعرفي - الصورة الثعرية - البلاغة - الأسلوبية.

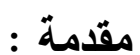

لا يمكن البحث عن الوشـائج والصـلات بين البلاغة العربيـة القديمة والمنـاهج النقديـة

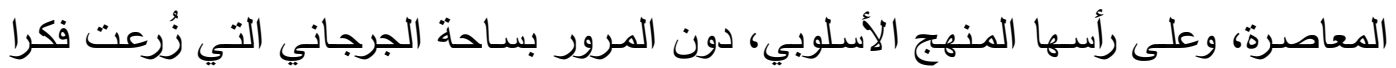
لغويا فأنثرت نظرات علمية دقيقة من حيث طرحُها، غنية من حيث نتائجها. وإذا حاولنا ربط

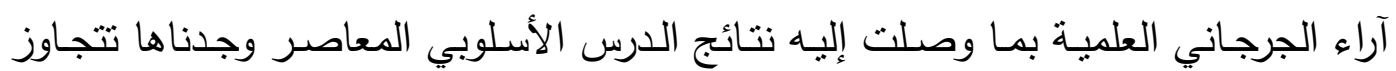

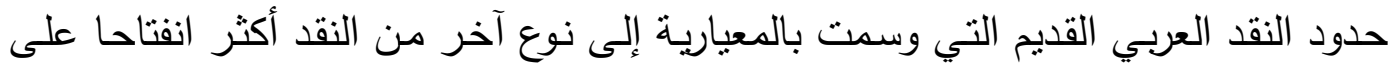

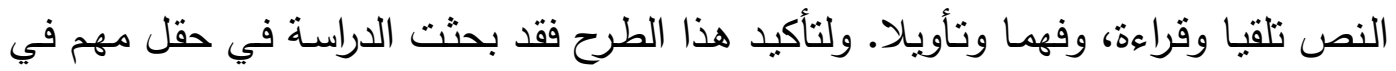
النقدين البلاغي والأسلوبي على حدّ السواء هو حقل (الصورة الثعرية) ودورها في الارتقاء باللغة من العادية التواصلية إلى الإبداعية التأثيرية من خلال الدراسات النصيّة للجرجاني في الني 
كتابيه (دلائل الإعجاز وأسرار البلاغة)، وأبحاث جون كوهن الأسلوبية في كتابيه ( بنيـة اللغة الثعرية واللغة العليا).

ومن النقاط العلمية التي قارنت فيها بين الباحثين، وبالتالي بين البلاغة والأسلوبية،

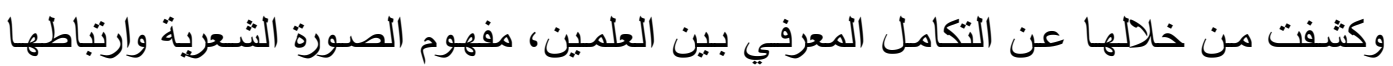

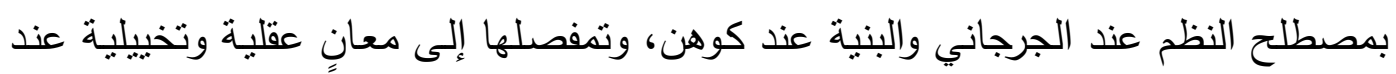
الأوّل، ودلالات المطابقة والإيحاء عند الثاني. كما تتاولت شكلا مهما من أنثكال الصورة

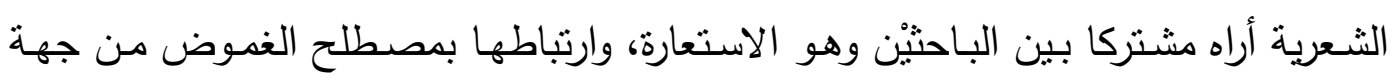

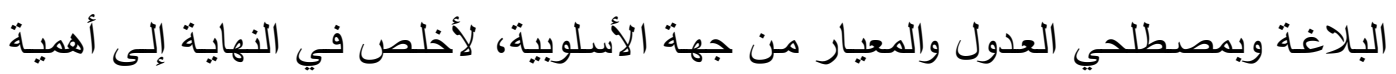
دور المنلقي في قراءة وفهم الصورة الثعرية وفلكّ طلاسمها.

\section{1 - تكامل مفهوم الصورة بين البلاغة والأسلويية:}

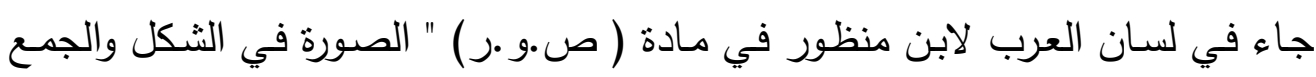
صور وقد صوره فتصور ، وتصوّرت الثيء توهّتت صورته فتصوّر لي والتصّاوير : التّماثيل. قال ابن الأثير: الصورة ترد في لسان العرب على ظاهرها وعلى معنى حقيقة الثيء وهيئته

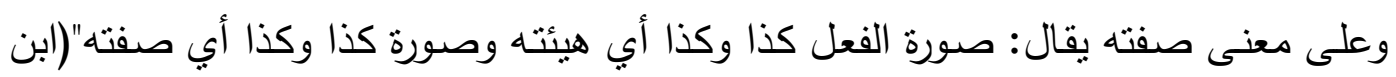

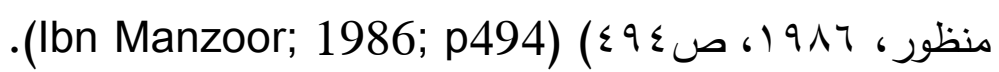

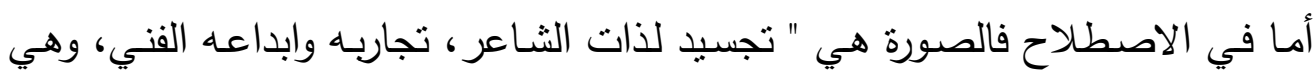

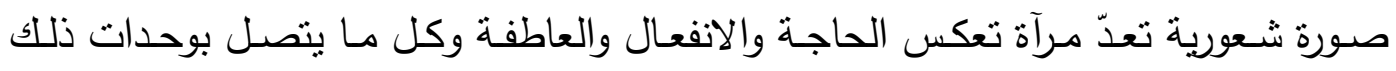

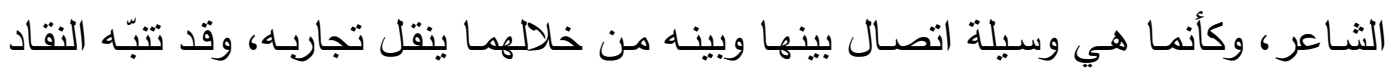

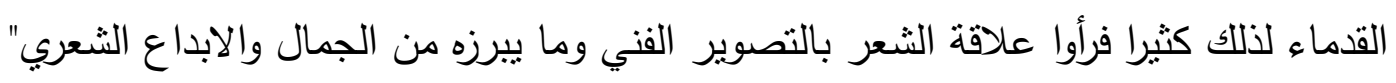

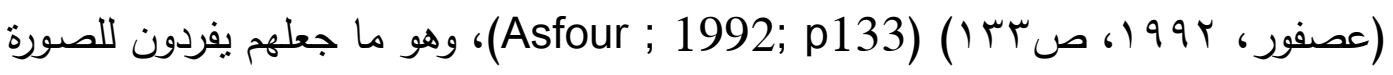
الثعرية بابا في دراساتهم النقدية والبلاغية. ومن أهم الوسائط المحدّدة لمفهوم الصورة عند الدارسين العرب القدامى، ارتباطها باللغة لفئة

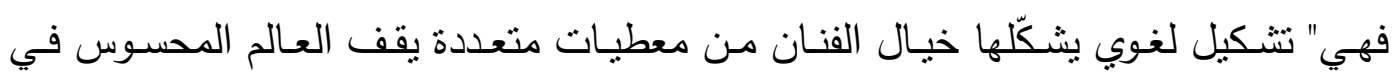

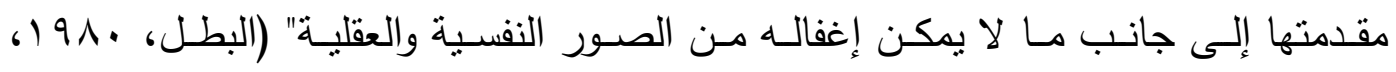

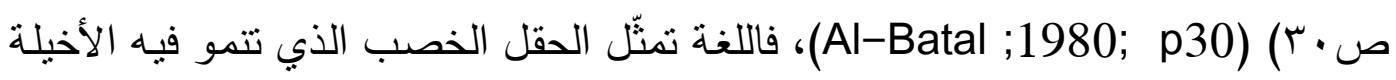

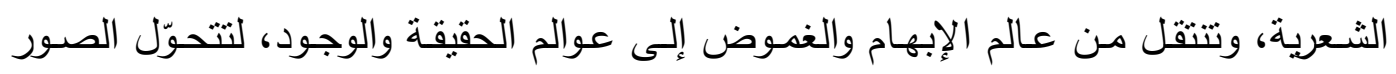

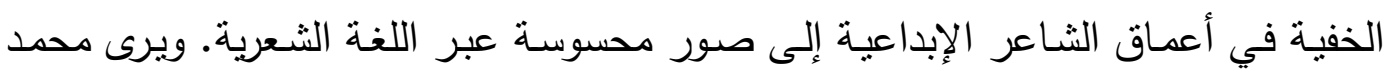

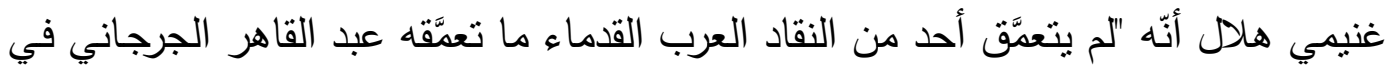

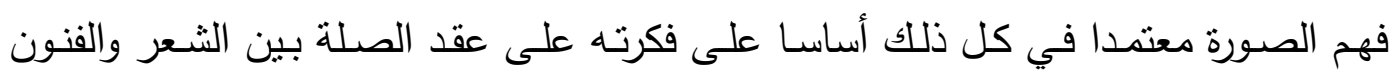

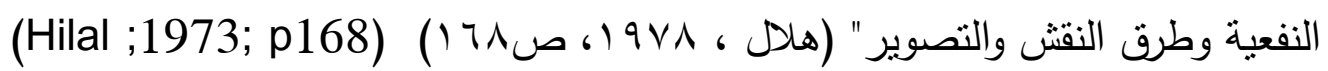


فالجرجاني يعتقد أنّ الصورة هي أحد أوجه البيان في اللغة، بل هي أحد وسائط المعاني السامية والنبيلة التي تسمو باللغة إلى مراتب الفن، يقول : "ومن الفضيلة الجامعة فيها أنّها

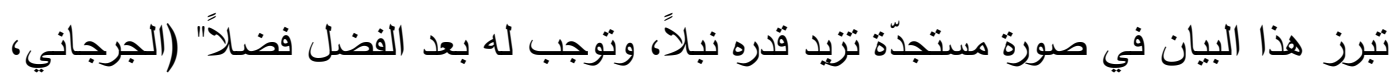

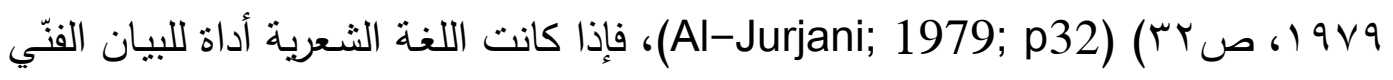

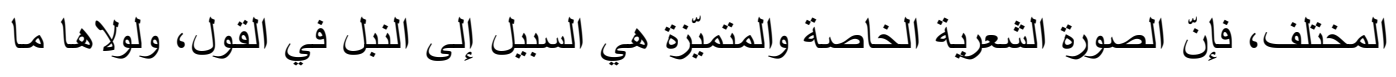
حاز الثعر ما ينسب إليه من فضل في التعبير الراقي.

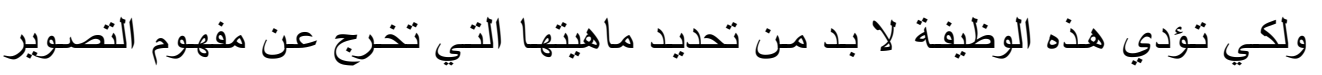

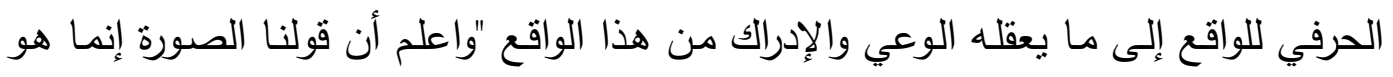

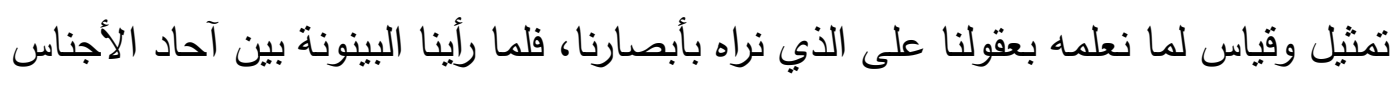

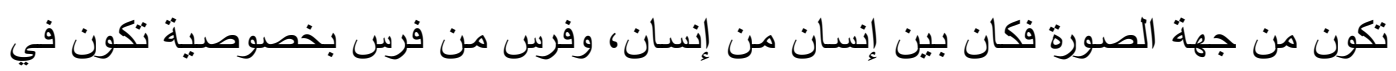

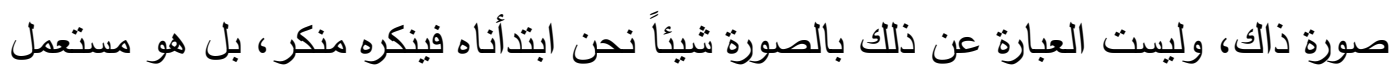

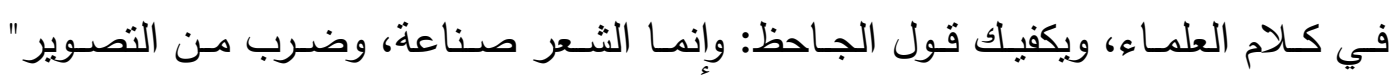

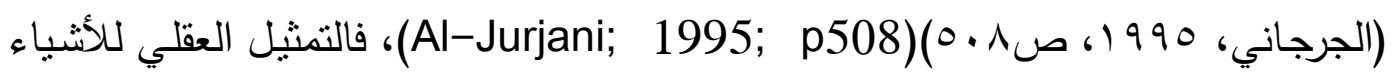

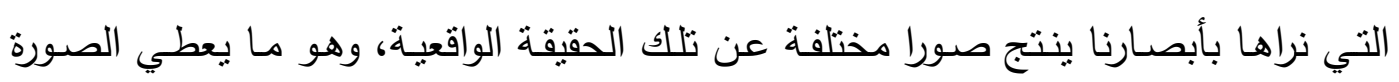

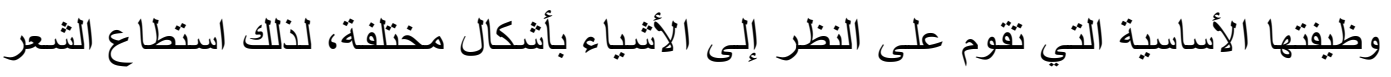

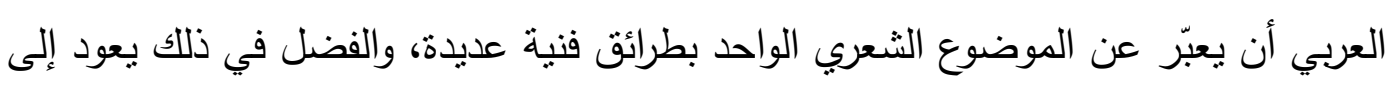
ميزة التصوير •

أما علم الأسلوب فقد حاول من خلال أبحاث جون كوهن John Cohen إقامة

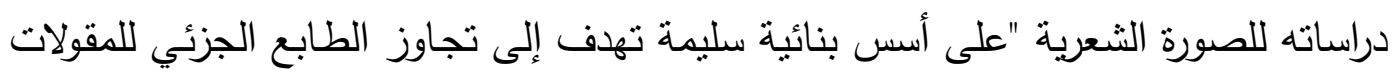

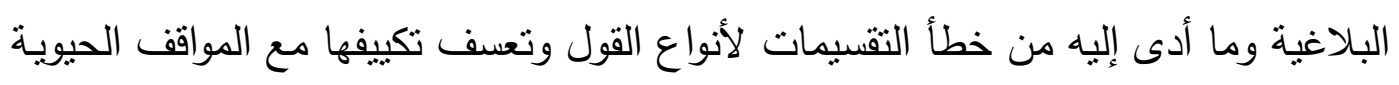

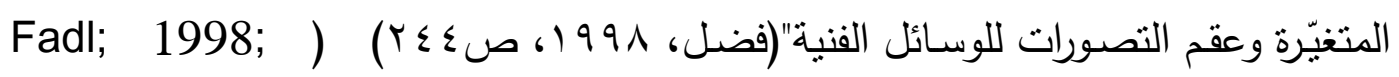

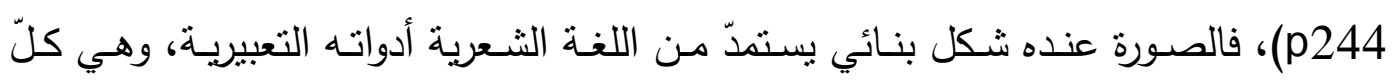

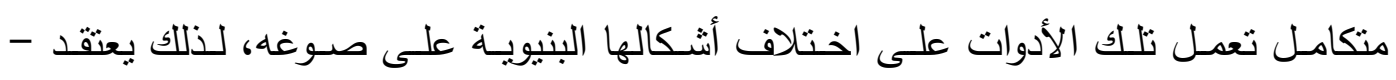

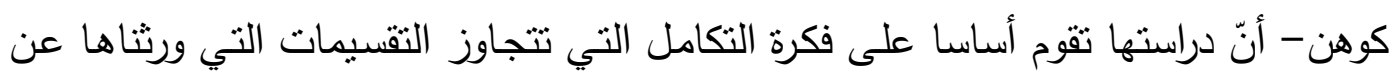

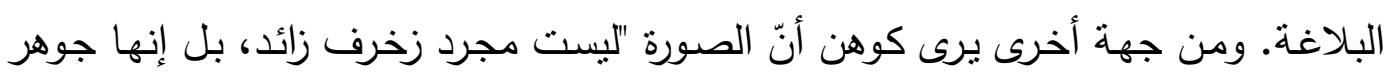

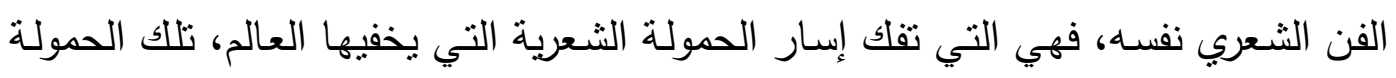

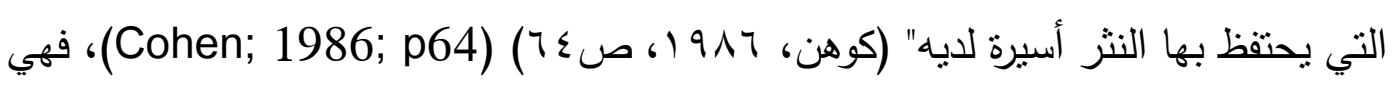

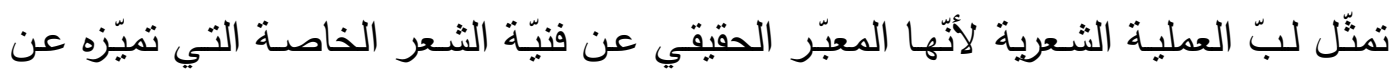

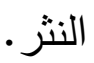


وهذه النظرة العميقة للصورة لا تختلف كثيرا عن نظرة الجرجاني، بل إنّها يلنقيان في

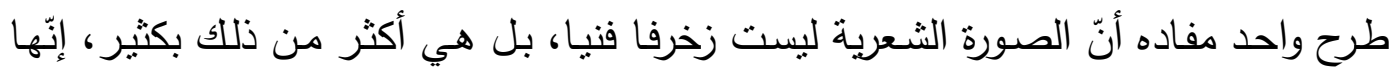
جوهر الفن الثعري عند كوهن، وهذا الجوهر لا يدرك إلاّ بالفكر العميق عند الجرجاني. r- لغة الصورة الثعرية من النظم البلاغي إلى البنية الأسلوبية:

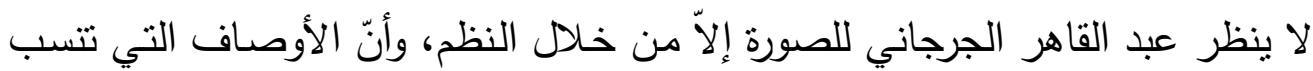

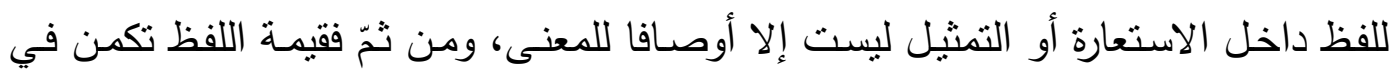

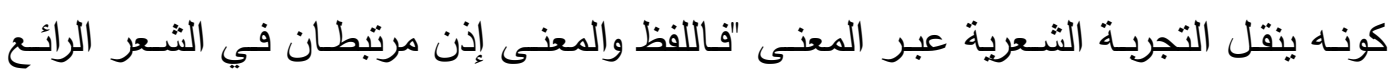

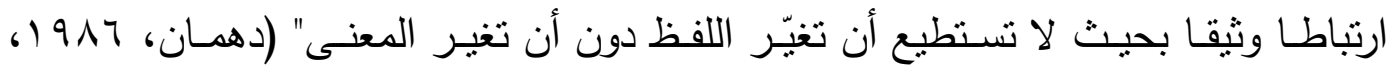

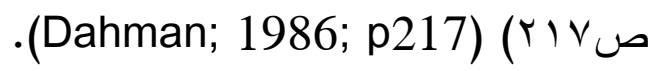
لذلك يقرّر الجرجاني أنّ سرّ جمال الصورة هو النظم الجامع بين اللفظ والمعنى، فيقول:

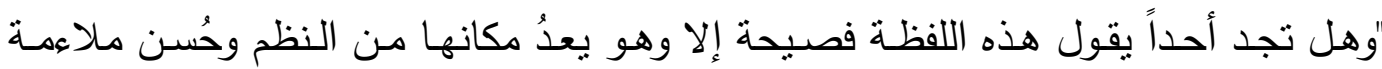
معناها لمعاني جاراتها وفضل مؤانستها لأخواتها، وهل قالوا لفظة متمكنة ومقبولة وفي خلافه قلقة ونابية ومستكرهة إلاّ وغرضهم أن يعبّروا بالتمكن عن حسن الاتفاق بين هذه من جهة وهنة

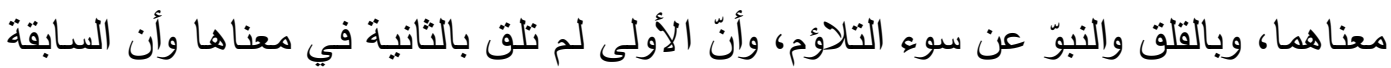

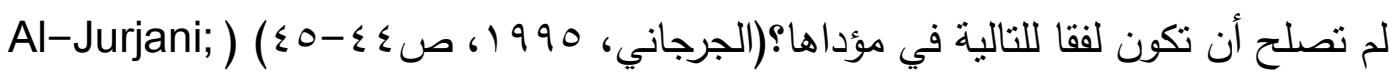
.(1995; p44-45

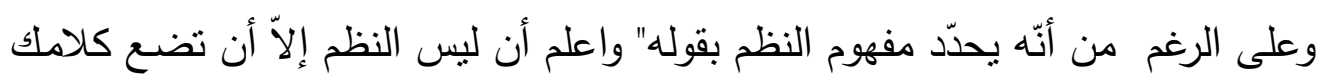

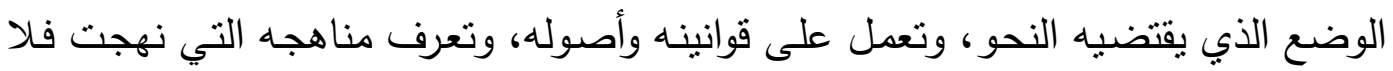

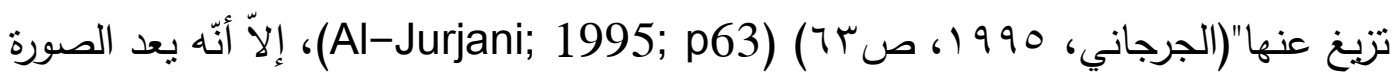

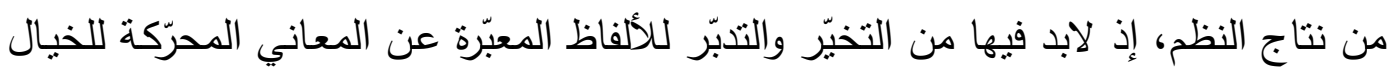

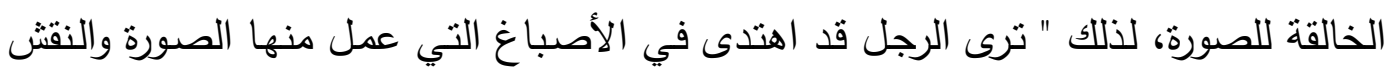

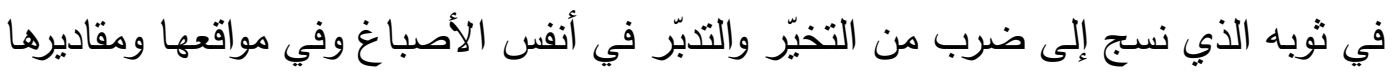

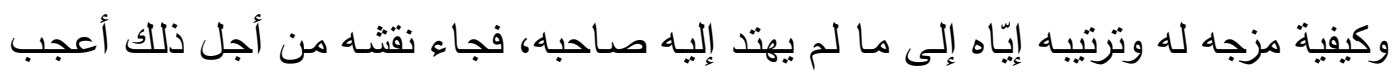

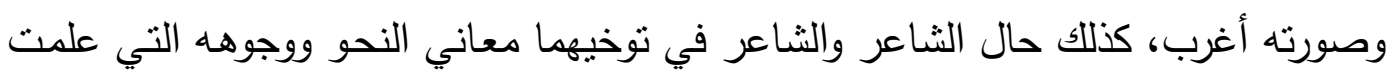

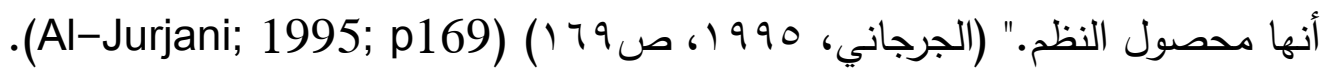

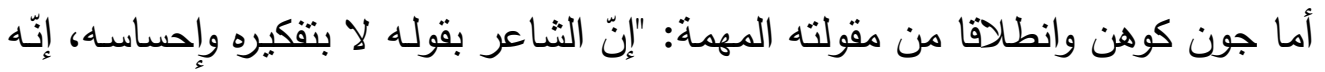

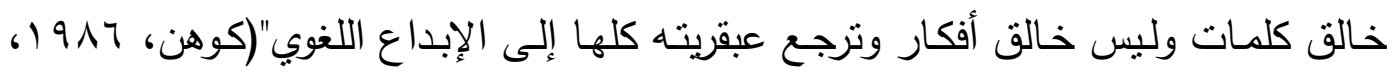

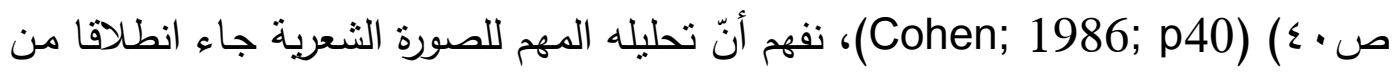
البنية اللغوية التي تعطيه أهمية كبيرة. 
وقد نبّه كوهن إلى الدور الذي تؤديه اللسانيات في تفسير اللغة باللغة وذلك ما يتوجب

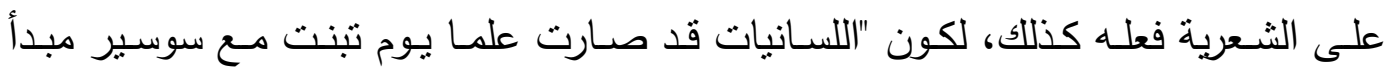
المحايثة، أي تفسير اللغة باللغة نفسها، ويجب على الثعرية أن تثتبى المبدأ نفسه، فالثتعرية

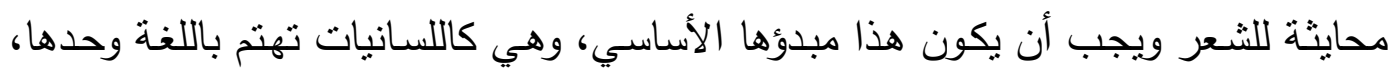

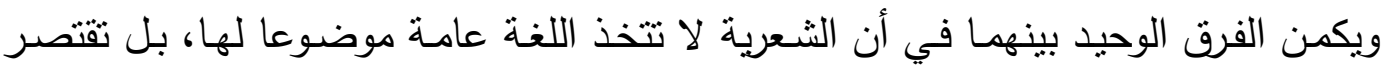

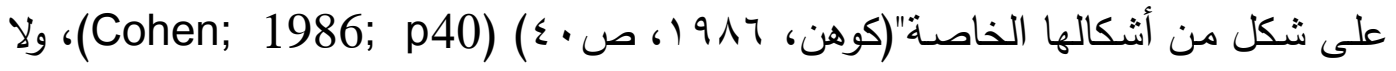
يكتمل الفن الثعري عند جون كوهن إلا حين يستغل كل الأدوات اللغوية والفنية التي تضفي

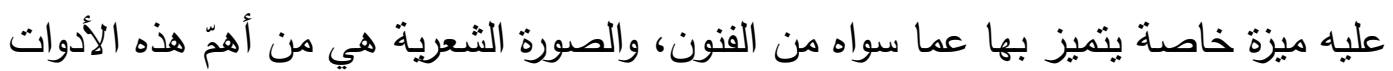
وقد اصطلح عليها بالتركيب البلاغي.

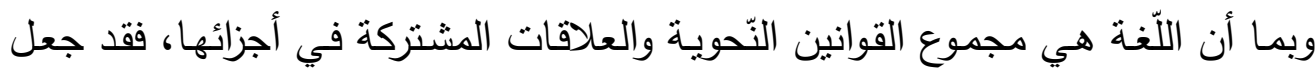
التركيب البلاغي خرقا لقوانين اللغة، و " إنّ دراسة هذه المخالفة لقانون اللغة تمرّ بمستوبين

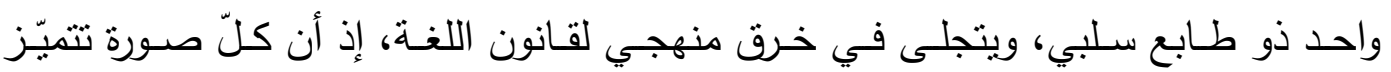

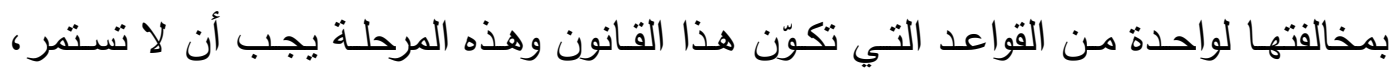

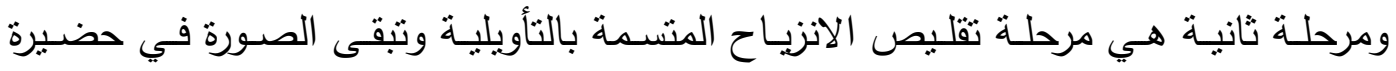

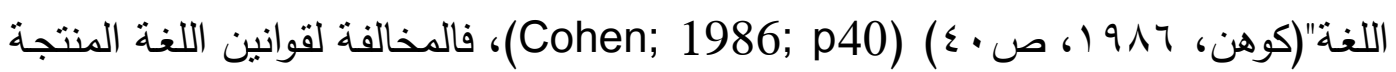

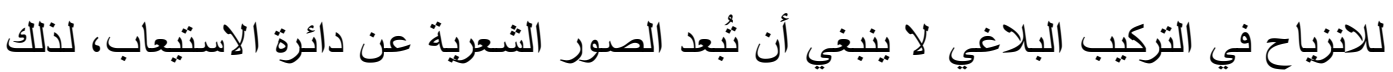

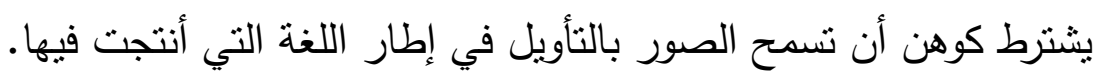

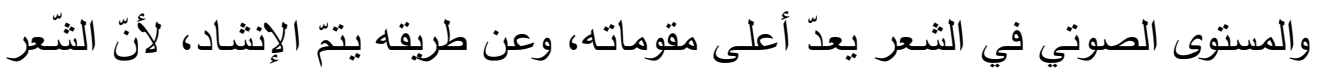

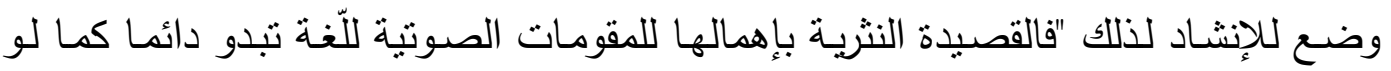

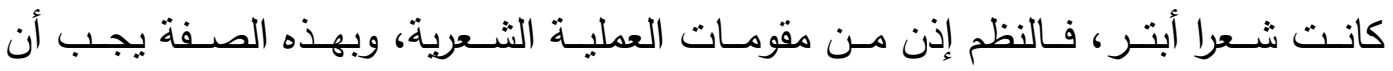

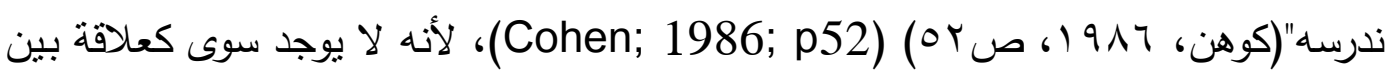
الصوت والمعنى، وهو ما يهب التركيب البلاغي قدرة أكبر على التأثير من خلال التعبير النغي الذي يتضافر مع التعبير التشكيلي.

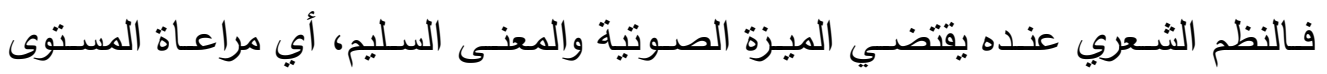

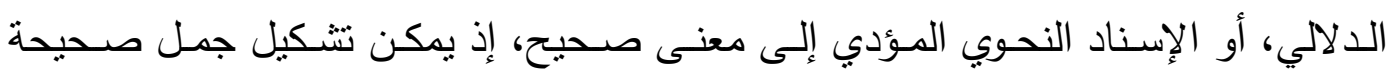

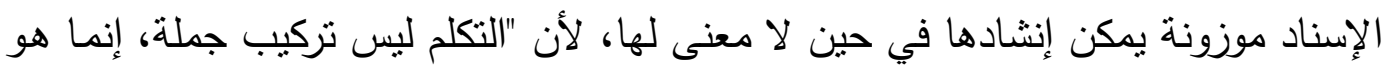

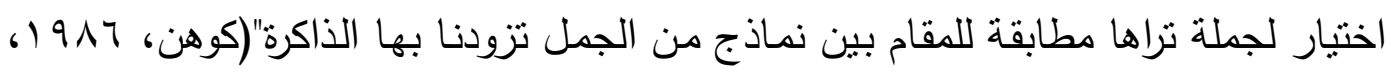
صل • ( ) (Cohen; 1986; p107) تتطلق من إحساسنا اللغوي الخاص لكي تخبرنا عمّا

$$
\text { هو صحيح أو غير صحيح. }
$$


كما أثنار إلى أهمية النحو والصرف في شعرنة الكلام، فضـلا عن المستوى المعجمي والصوتي، وأن هناك علاقة متينة للنحو مع باقي المستويات سوى التضمين العروضي، لأنّه يقتضـي أحيانـا "تعارضـا بين الوزن والتركيب، والقافيـة الحقيقيـة ليست نحوبـة، والمنافرة تقوم

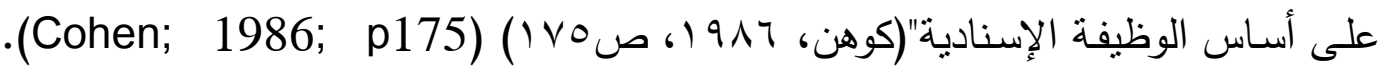
وانطلاقا من ارتباطها باللغة، حدّد كوهن وظيفة الصورة التي يراها "تكثيفية ، فهي لا تغيّر محتوى المعنى وإنما تغيّر شكله، إنّها تعبر من الحياد إلى التكثيف، وبكثف التحليل أنّ للصورة ملمحين اثثين، فهي من الناحية البنيوية شمولية، ومن الناحية الوظيفية تكثيفية، إنّها

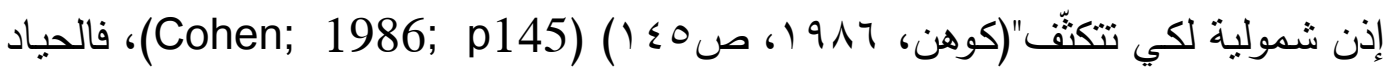
هو التعبير عن المعنى بلغة تواصلية عادية، والتكثيف تعبير عن المعنى نفسه، ولكن بشكل أعمق من خـل التصوير الشعري، والشمولية هي الإطار البنيوي الذي تحيا داخله أدوات اللغة التي يستعين بها الثاعر في الخلق الثعري. فالثـعر في نهايـة المطاف عند الجرجـاني وكوهن فن أداته اللغـة، سواء عبّر عنها الأول بالنظم أو عبّر عنها الثاني بالبنية، فكلاهما يعتقد أنّ التركيب المخصوص لوحدات اللغة البنائية هو ما ينتج الصور الثعرية البديعة.

ب-دلالات الصورة الشعرية من المعاني العقلية والتخييلية إلى دلالتي المطابقة والإيحاء: تحدّث الجرجاني عن المعاني التخيلية والمعـاني العقلية، فما وافق العقل وافق معاني النحو ومـا خالف ذلك فهو تخييـل وقد اعتدّ الجرجاني بالتخييل كثيرا، وجعله قوام الثـعر وشرحه بقوله: "وجملة الحديث الذي أربده بالتخييل ما يثبت فيه الثـاعر أمرا هو غير ثابت أصسلا، ويدّعي دعوى لا طريق إلى تحصيلها ويقول قولا قد يخدع فيه نفسـه و يربها ما لا

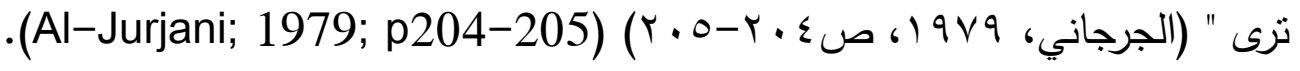
وقد استمدّ هذا التقريق من خلال حديثه عن أضرب الكلام المختلفة، فالمتكلم العادي لا يستعمل اللغـة منلمـا يستعملها المبـدع في نصوصـه الإبداعية و نراكيب الكـلام العـادي، تختلف كل الاختلاف عن التراكيب الإبداعية وإذا كان المقصود من النوع الأول هو إيصـال المعنى إلى المتلقي دون جهد، فإنّ قصد الثاني هو إيصال المعنى ومعنى المعنى يقول: " الكلام على ضربين، ضرب أنت تصل منه إلى الغرض بدلالة اللفظ وحده وذلك إذا قصدت أن تخبر عن زبد بالخروج من الحقيقة فقلت: خرج زيد وبالانطلاق عن عمرو، فقلت عمرو منطلق وعلى هذا القياس، وضرب آخر أنت لا تصل منـه إلى الغرض بدلالة اللفظ وحده ولكن يدلك اللفظ على معناه الذي يقتضيه موضوعه في اللغة، ثم تجد لذلك المعنى دلالة ثانية تصل بها إلى الغرض ومدار هذا الأمر على الكناية والاستعارة والتمثيل، فالمعنى هو المفهوم من ظاهر اللفظ، والذي تصل إليه بغير واسطة، ومعنى المعنى هو أن تعقل من 


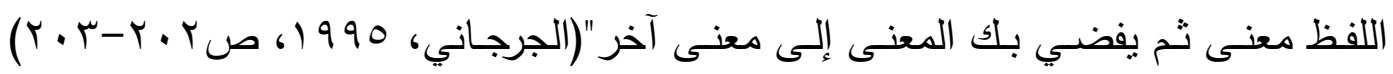
(Al-Jurjani; 1995; p202-203)، فكأنّ عبد القاهر الجرجاني يصف لغة الثعر بأنها

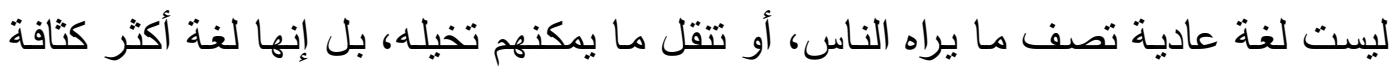
نسمعها فلا نرى من خلالها إلا ضبابية في المعنى، تدفع القارئ إلى البحث في أنهاه أغوارها، ومحاولة كثف خباياها.

أما المعاني العقلية فهي التي تعتمد التراكيب اللغوية الأكثر قربا إلى ذهن القارئ، والتي يمكن بالرجوع إليها، الكثثف عن معنى المعنى ومدار هذا الحديث هو عن الاستعارة والتمثيل

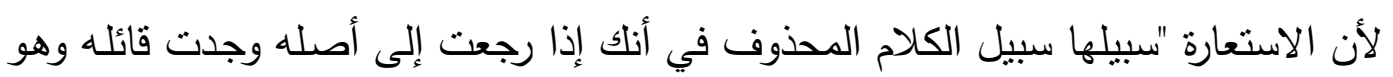

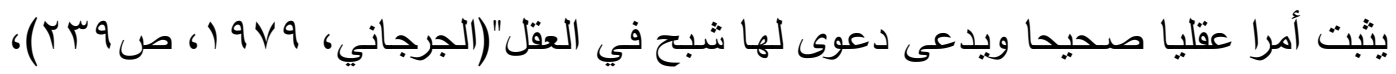

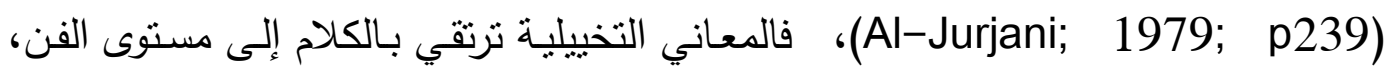
والمعاني العقلية تسمح بفهمها وتأويل معانيها.

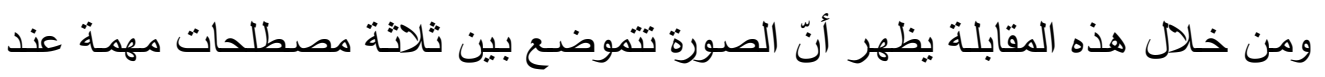

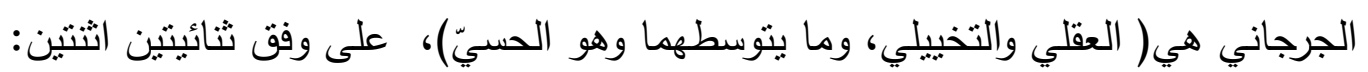

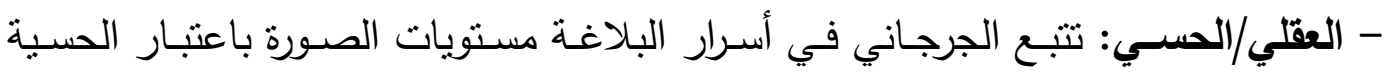

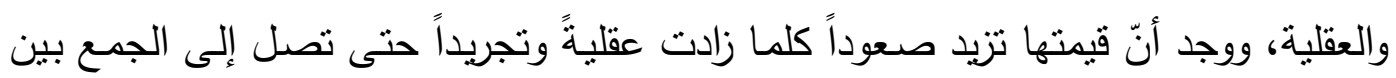

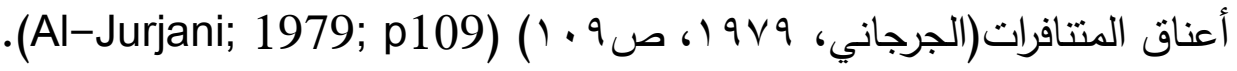
- العقلي/التخييلي: ثم جعل المعنى العقلي في مُقابل التخييلي، فالعقلي هنا ما لا يعتدّ فيه بالأخذ لأنّه مشترك، أي غبر شعري، العقلي هنا هو الدنطقي المجرّد، والتخييلي هو المقابل

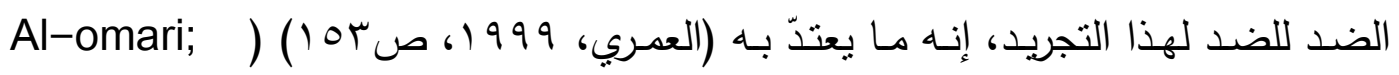

.(1999; p153

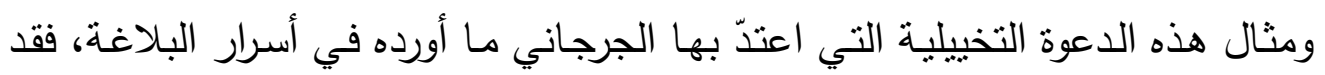

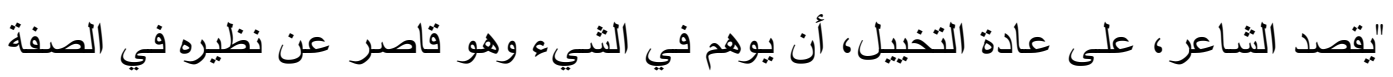

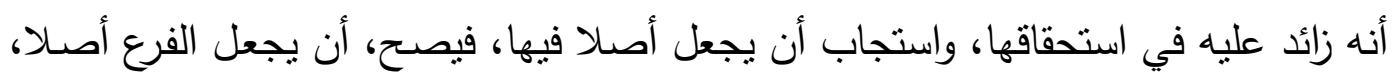

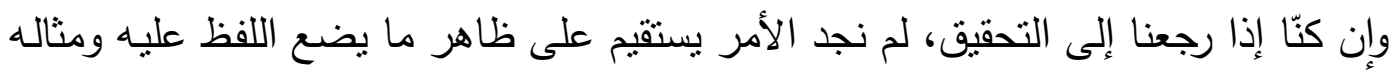

$$
\text { قول محمد بن وهيب: }
$$

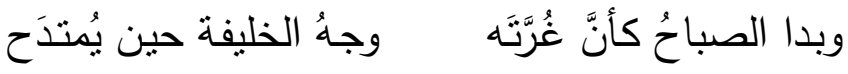

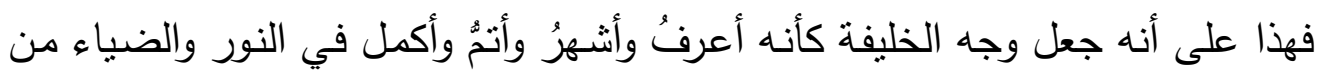

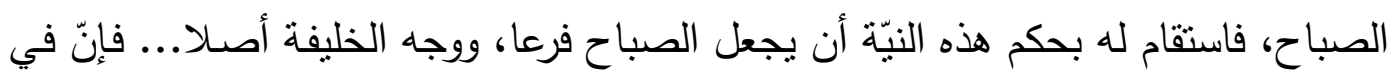

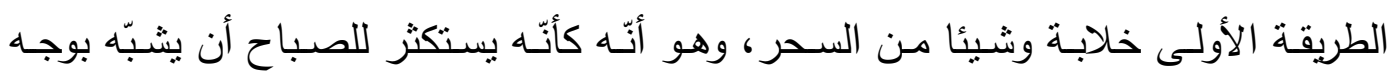

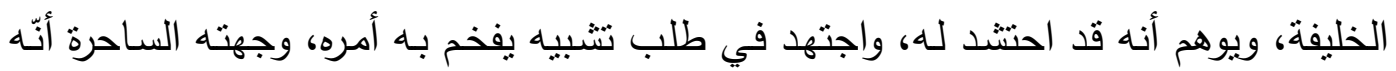




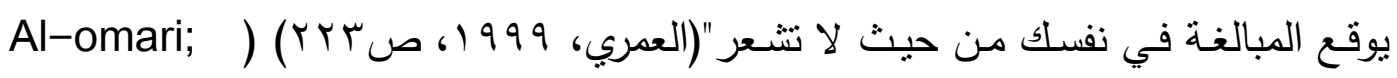
.(1999; p153

أما جون كوهن فقد نظر إلى الصورة من زاوية التفريق بين الثعر والنثر، حيث ميّز

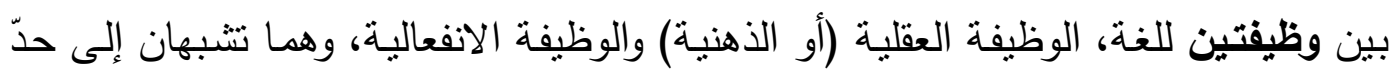

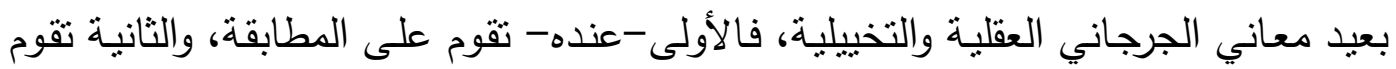

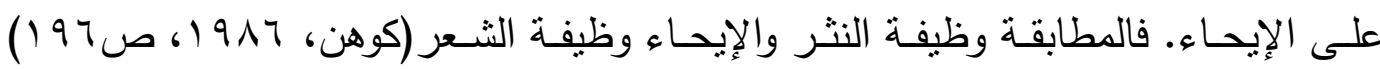
(Cohen; 1986; p196)، واللغة الثعرية عنده هي خرق القانون المطابقة للواقع ولقواعد اللغة، لتحقيق البعد الإيمائي في النص الإبداعي ولتحديد التركيب البلاغي من جهة أسلوبية

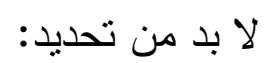
- دلالة المطابقة: وهي اللغة التي تطابق الواقع، ووظيفتها تقريب الثنيء بصورة واضحة، وهي المعاني العقلية عند الجرجاني. - دلالـة الإيحاء: وهي كثف الباحت علث عن محاولة المبدع لإحالته على المرجع بطريقة

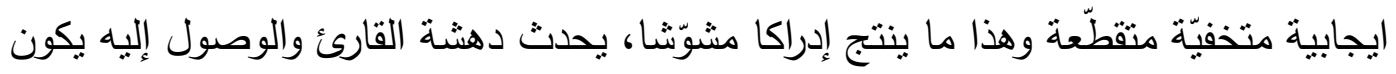

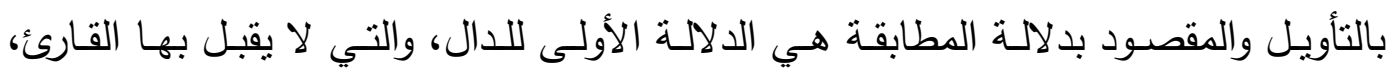

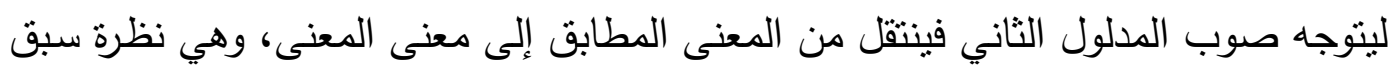
الإثشارة إليها عند عبد القاهر الجرجاني. وللوصول إلى المدلول الثاني "فالثناعر يؤثر في الرسالة لأجل تغيير المعنى، وإذا كان

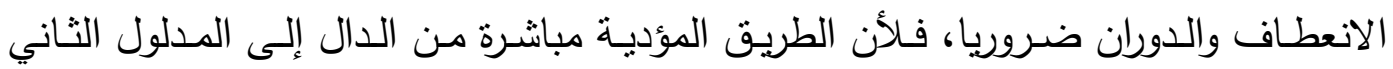

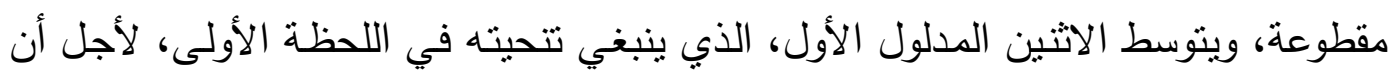

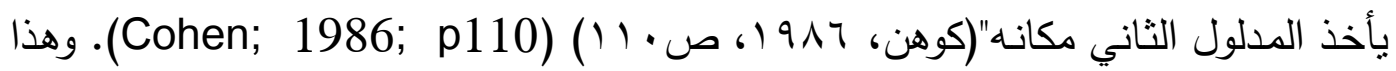
التطابق بين أراء ومصطلحات الجرجاني وكوهن يبرز عمق التفكير النقدي الذي تميّزت به بهانه

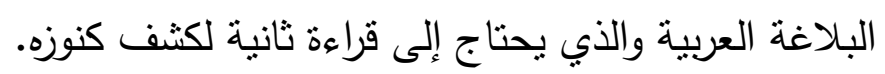

\section{ع - الغموض في الصور الثعرية بين الغرابة والانزياح:}

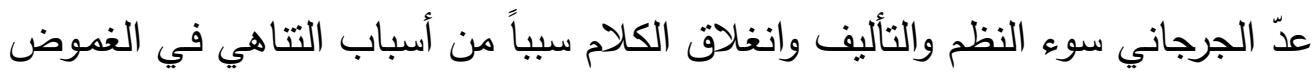
إلى درجة التعقيد، يقول: "واعلم أن لم تضق العبارة ولم يقصر اللفظ ولم ينغلق الكلام في

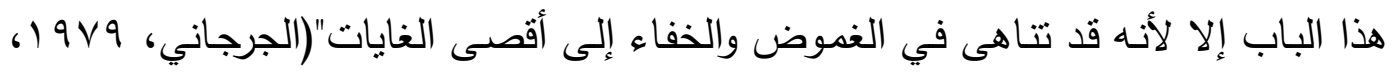
ص صYro) (Al-Jurjani; 1979; p272)، ويكثف هذا الموقف للجرجاني عن إدراكه

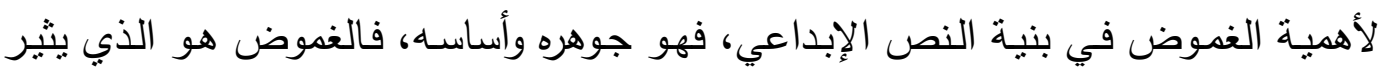

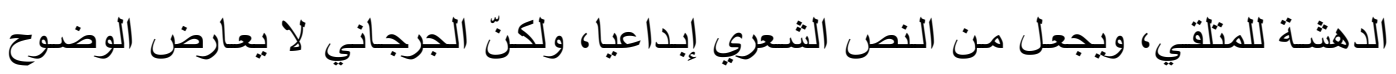


والقرب في المعاني الأدبيـة شريطة أن لا يصل هذا الوضوح إلى السطحية والضعف مما يبعد النص الإبداعي عن جوهره الفني. ولكنّ وضوح النص في ظاهره لا يعني أنّه سطحي، فقد يبدو القول التالي: (كالبدر

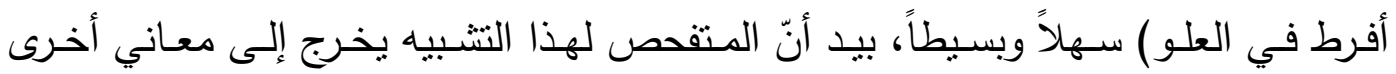
إضافية تحتاج إلى التفكير ، يقول الجرجاني: "هذا وليس إذا كان الكلام في غاية البيان وعلى أبلغ ما يكون من الوضوح أغناك ذاك عن الفكرة إذا كان المعنى لطيفاً، فإنّ المعاني الثريفة اللطيفة لا بـ فيها من بناء ثان على أول، وردّ تال إلى سـابق، أفلست تحتاج في الوقوف على الغرض من قوله: كالبدر أفرط منه ووجه المجاز في كونه دانياً شاسعاً وترقم ذلك في قلبك ثم تعود إلى ما يعرض البيت الثاني عليك من حال البدر ثم تقابل إحدى الصورتين بالأخرى وتردّ البصر من هذه إلى تلك وتتظر إليه كيف شرط في العلو الإفراط ليشاكل قوله شاسع لأن الشسوع هو الشديد من البعد ثم قابله بما لا يشاكله من مراعاة التتاهي في القرب التب فقال جد قريب، فهذا هو الذي أردت بالحاجة إلى الفكر، وبأن المعنى لا يحصل للك إلا بعد هو

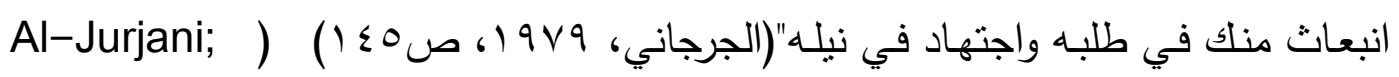
1979; p145)، فالغموض يحتاج إلى قراءة متأنيّة، وعبارته (بناء أوّل على ثانٍ) تدل على الدلالتين السطحية والعميقة، والثانية لا تحصّّ إلاّ بعد جهد. كما استعمل الجرجاني مصطلح الغرابة ليشير إلى الغموض الفني في العمل الابداعي، يقول: "والمعنى الجامع في سبب الغرابة أن يكون الثبه المقصود من الثيء مما لا بينزع إليه الخاطر ، ولا يقع في الوهم عند بديهة النظر إلى نظيره الذي يثبهه بل بعد ثتبت وتذكر وفكر للنفس في الصور التي تعرفها وتحريك الوهم في استعراض ذللك واستحضار ما غاب

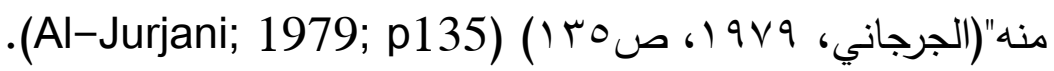
ثمّ أثنار الجرجاني إلى مرادفات أخرى للغموض مثثل التعقيد غير المقصود، والتعمية، وهذا ما يكسب العمل الابداعي قوة وخصوصية فنية، يقول: "وأشباه ذلك مما ينال بعد مكابدة الحاجـة إليـه، وتقدم المطالبـة من النفس بـه، فـإن قلت: فيجب على هذا أن يكون التعقيد والتعمية وتعمّد ما يكسب المعنى غموضاً مشرفاً له وزائداً في فضله، وهذا خلاف ما عليه الناس، ألا تراهم قالوا: إن خير الكلام ما كان معناه إلى قلبك أسبق من لفظه إلى سمعك، فالجواب أني لم أرد هذا الحدّ من الفكر والتعب، وإنما أردت القدر الذي يحتاج إليه في نحو

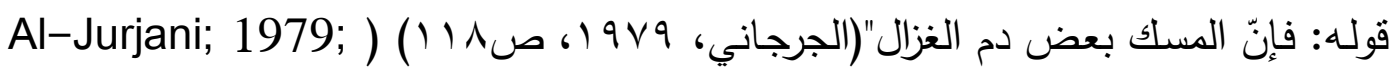
p118). فهذا الغموض لا ينقص من قيمـة الصـورة بـل هو من يعطيها قيمتها الإبداعيـة، يقول: "فإنك تجد الصورة المعمولة فيها كلّما كانت أجزاؤها أثندّ اختلافا في الثكل والهيئة، ثم هئ 
كان التلاؤم بينها مـع ذلك أتمّ، والاتـلاف أبين كان شـأنها أعجب والحذق لمصـورها

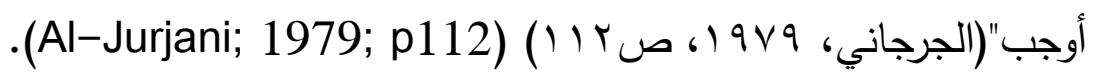

ولكنّ موسى ربابعة يرى أنّه" إذا كانت الغرابة توصف عند الجرجاني في قوتها بأنّها

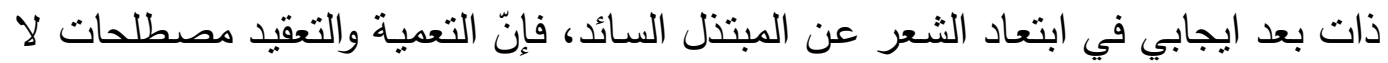

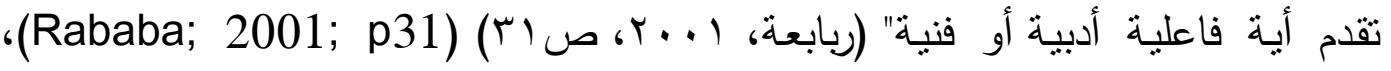

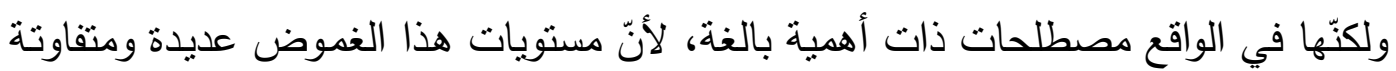
الثدّة، والتعبير عن ذلك التفاوت يحتاج إلى مصطلحات الثطات الخاصة.

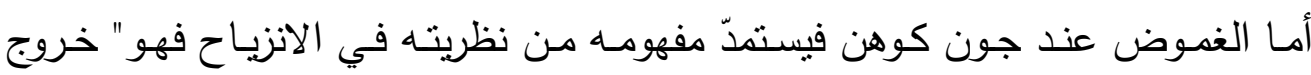

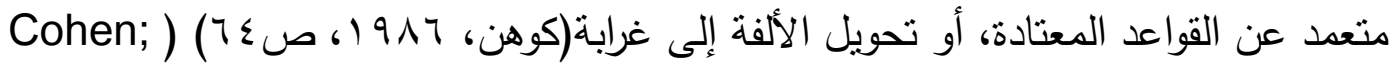

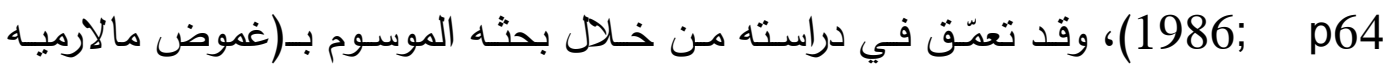
(Mallarmé

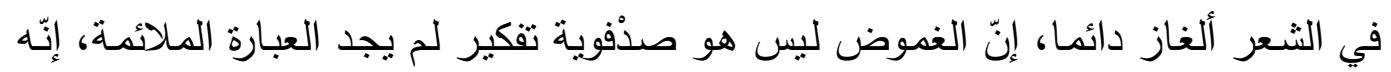

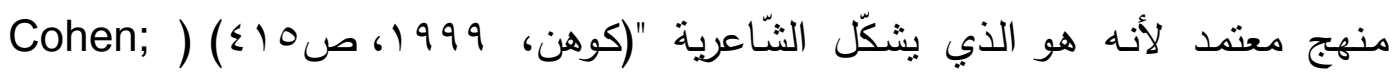
1986; p415)، فالغوض عنده هو مصدر الثاعرية الأدبية.

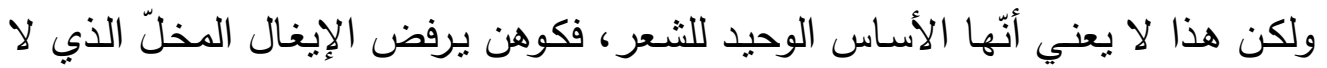

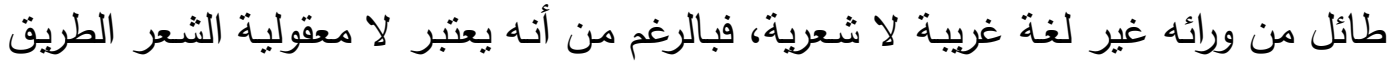

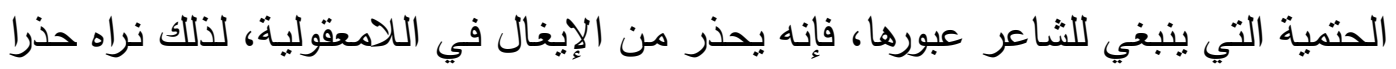

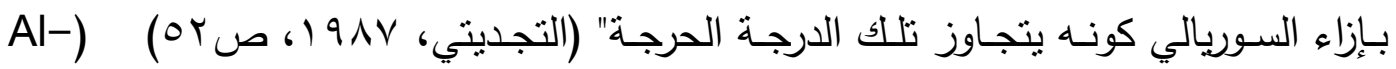
(Tajditi ; 1987; 052

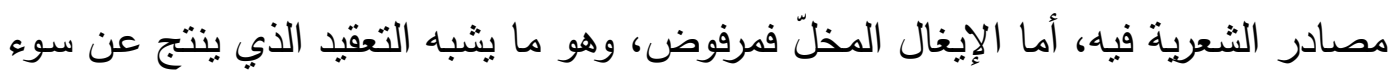
النظم والذي رفضه الجرجاني. ويثير كوهن في كتابه" اللغة العليا " في مواضع متفرقة إلى الغموض في الثنعر وما

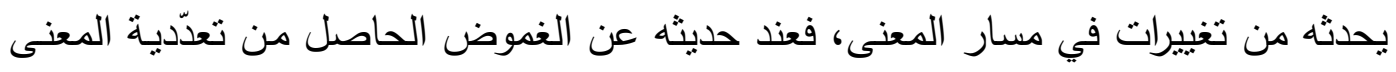

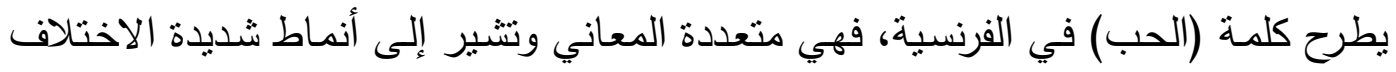

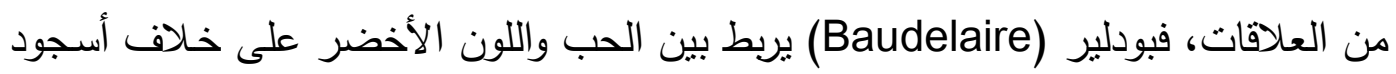

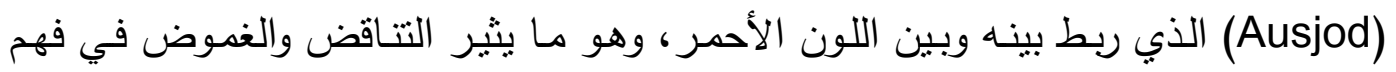

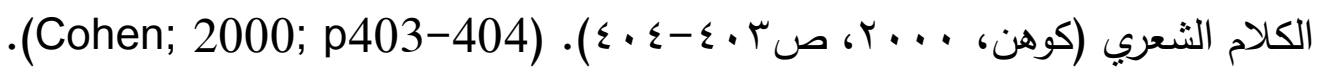

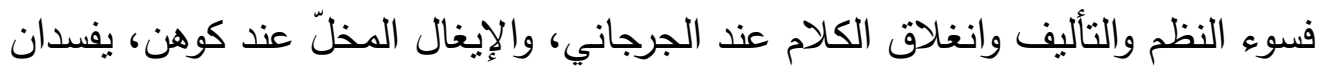

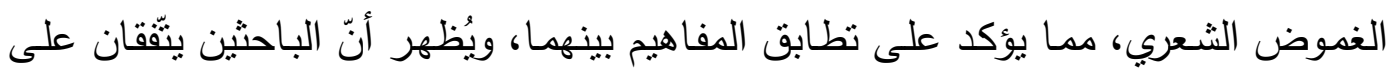
أنّ الغموض المستحب في الثعر هو ما زاد المعنى جمالا والقارئ دهثة، والثعر ثأثثرا. 


\section{ه - المعيار والعدول في الصور الشعرية بين البلاغة والأسلويية:}

يعرّف عبد القاهر الجرجـاني العدول في أسـرار البلاغة بقوله: "وإذا عُدل بـاللفظ عمَّا يوجبه أصل اللغة، وُصف بأنه مجاز ، على معنى أنهم جازوا بـه موضعَه الأصلي، أو جاز

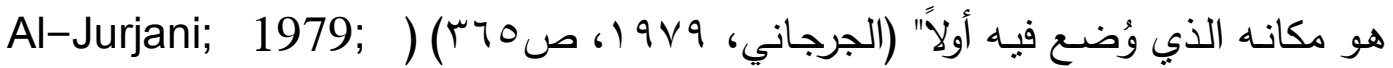
p365)، فالمجاز هنـا شـرح للتجـاوز الذي يمرّ من خلاله اللفظ من استعماله العادي إلى هـ استعمال جديد لم يكن له في الأصل لالالة خاصة أرادها المتكلّم. وهذا العدول والتجاوز لا يكثنف عنه إلاّ المعيار الذي حدّده بقوله" وأنه المعيار الذي لا له يتبيّن نقصان كلام ورجحانه حتى يعرض عليه، والمقياس الذي لا يعرف صحيحاً من سقيم

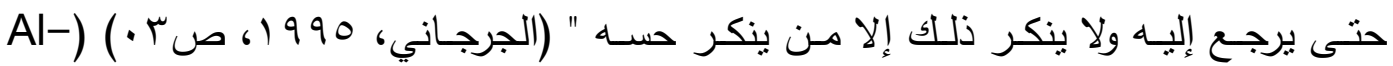
.(Jurjani; 1995; p03

والملاحظ أنّ الجرجاني نتبّه إلى ثنائية اللغة الثعرية واللغة المعيارية لكنّه لم يصرح بها بشكل مباشر ، إلاّ أنّه أومأ إلى مستوبات الكلام التي بدأها من الكلام العادي وصولا إلى إلى الكلام المعجز، ولا يمكن التفرقة بين هذه المستويات من الكلام دون الوقوف على المستوى

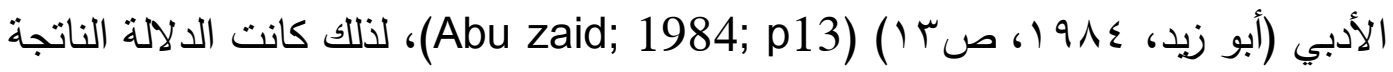
عن الأصل والعدول عنه مختلفة، يقول الجرجاني:" الكلام على ضربين ضرب أنت تصل منه إلى الغرض لدلالـة الفظ وحده... وضرب آخر أنت لا تصل منـه إلى الغرض لدلالـة اللفظ وحده" (الجرجاني، 990 (، صسr I) (Al-Jurjani; 1995; p173). ومن الأمنلة التي أوردها الجرجاني للتعبير عن القيمة الفنية والنقدية للعدول أنّ "المزية في قوله تعالى: (واشتعل الرأس شيبا) ليس للاستعارة وحدها ولكن لنظم العبارة ومجيء الرأس فاعلا و (الثيب) تمييزا، ولو قيل (اشتعل شيب الرأس) لذهبت تلك المزية (الجرجاني، 990 (99 ص9l-Jurjani; 1995; p69) (Al)، فالتركيب البلاغي هنا نتج عن التحوّل من التركيب العادي إلى التركيب المنزاح، فنشأت الصورة الثعرية من نظم مغاير احتلت فيه الوحدات اللغوية مواضع ليست لها في الأصل.

وهذا العدول يشبه ما رأينا عند جون كوهين في ما اصطلح عليه بـشعرية الانزياح" إذ حاول أن بطوّر البلاغة القديمة بإدخالها إلى دائرة الأسلوبية، وتتجلى نظريته في ما أسماه خرق الثعر لقانون اللغة، فالثـعر طبقاً لهذه النظرية "لبس نثراً يضاف إلبه شيء آخر ، بل إنّه نقيض النثر، غير أن المسألة ليست مطلقة، فثمة من بميز بين ضربين من الثعرية أو الجمالية الأول يسمى بجمالية الممانلة حيث تحدّد قيمة الأشكال الفنية بمدى احترامها للقواعد وبكون كلّ خرق فيها علامـة ضـعف، والثاني بطلت عليه اسم "جماليـة المعارضـة" حيث

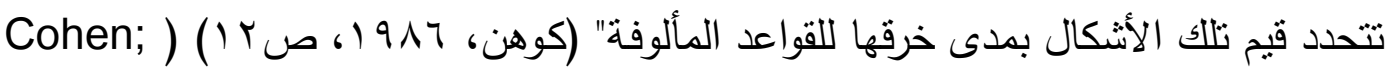


1986; p12)، والصـور الثـعرية مـن النوع الثاني الذي بعتمد الانزبـاح أساسـا لثـرنة الإبداع، من خلال جماليات المعارضة التي يقيمها الثاعر بين الوحدات اللغوية. لذلك يقرّر جون كوهن أنّ "الأسلوب هو كلّ ما ليس شائعاً ولا عادياً ولا مطابقاً للمعيار

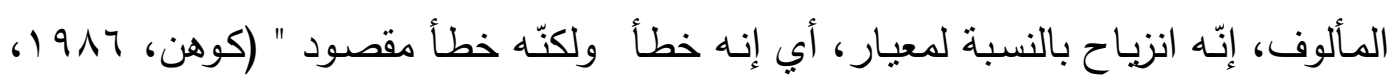
صه 1) (Cohen; 1986; p15). ويضيف في موضع آخر من الكتاب الذي ترجمه أحمد

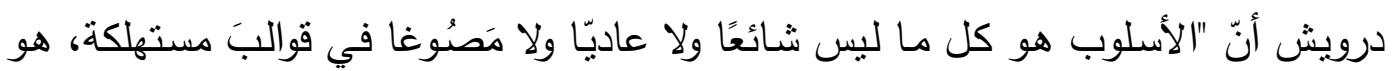

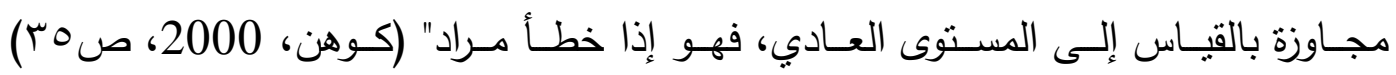
(Cohen; 2000; p35)، فجون كوهن بعد أن حدّد التركيب البلاغي بأنه نركيب لغوي محظ، ولا يمكن أن يخـرج عـن إطـار اللغـة حدد لنفسـه و للارسـين سـبيلين لاراسـة هـذا التركيب، أولهما تعيين الخرق الحاصل في اللغة وتحديد ماهيته بشكل دقيق، وثانيهما إعادة بناء هذا الخرق لإنشاء واقع جديد. ولأنّ الثَعر حين يخرق قوانين اللغـة ويحطّهـا لا يكون ذلك هو هدفه، وهي المرحلة الأولى، بل تكون منطلقا لإعادة بناء هذه اللغة بشكل آخر ذي مستوى عال إذ يعقب النقص هل الذي تسببه الصورة البلاغية إعادة بناء من طبيعة أخرى وتعتمد إعادة البناء على التأويل كما - ذكرنا سابقا - وهو المسمى عنده بدلالة الإيحاء التي تختلف عن دلالة المطابقة. وفضــلا عـن مصــلحي الإيحساء والمطابقـة في علاقتهمـا بالصـورة يضـيف كـوهن مصطلحي الدلالة التصريحية والدلالة الحافة في علاقتهما بالانزياح، فالخطاب الثعري عنده "يموت على صعيد الدلالة التصريحية لينبعث على صعيد الدلالة الحافة" (كوهن، 919 ) صז 9) (Cohen; 1986; p96). والانزياح عند كوهن يكون تحرّرا من سلطة المعيار كما رأينا في الاقتباسين السابقين، والمعيار المتعارف عليه يكون: 1- مناسبة الكلام لقواعد اللغة المعنية. r- واحدية الدلالة و تعيينها. r- مناسبة الدرجة للخطاب. وكلّ خروج عن هذه العناصـر هو انزياح لغوي، يخضـع لمبدأي الاستبدال والتركيب اللذين تخضع لهما اللغة عادية كانت أم إبداعية، والتحليل الأسلوبي لهذا المستوى يقوم على الى رصـد نـوعين مـن الانزياحـات: انزياحـات اسـتبدالية وانزياحـات نراكبيـة: أمـا الأولى فهـي الانزياحـات الناتجـة عـن تعـويض علامـة بعلامـة غيـر متوقعـة مـن قبـل المتلقي (كوهن،

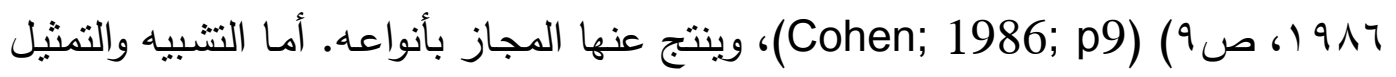
فهما عند كوهن من الانزباحات التراكيبية (Ecarts Syntagmatiques) ويخضـع هذا النوع من الانزياحات للجمع بين الوحدات اللغوية في تركيب لغوي واحد وهو تركيب بلاغي 
يقوم على الجمع بين وحدتين لغويتين حضوريين على أساس المشابهة "يعتبر انزياحا تراكيبيا بكون العلامتين تحتفظ باستقلالها وهذا أمر ساعد على ابرازه الروابط أو الوسائط المقالية (أدوات التشبيه) (كوهن، 919 (، صون •ـ) (Cohen; 1986; p40)، فالوحدتان اللغويتان الأساسيتان مذكورتان يمكن الاستعارة التي تحذف في أحدهما.

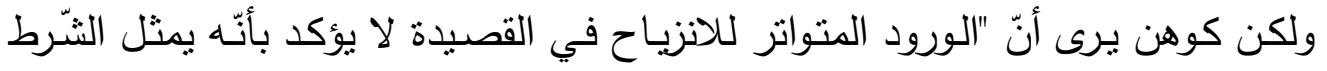

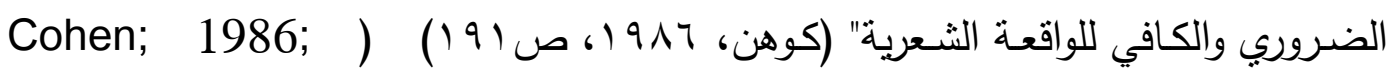

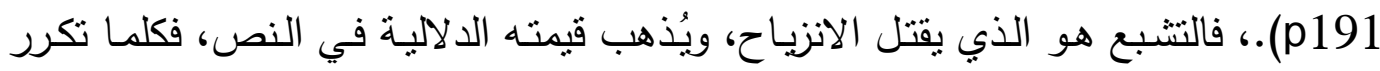

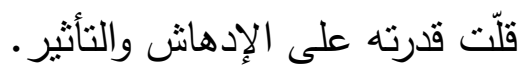

\section{צ-دور المتلقي في تأويل الصور الشعرية بين البلاغة والأسلويية :}

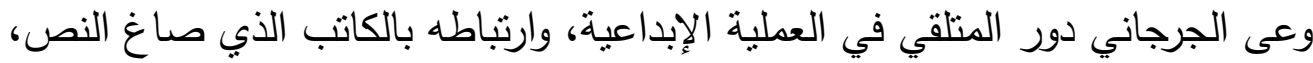

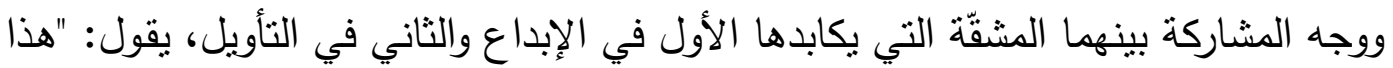

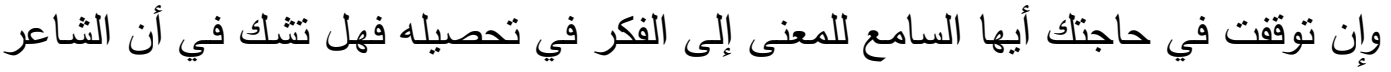
الذي أداه إليك، ونشر بزه لديك، قد تحمل فيه المشقة الثنديدة، وقطع إليه الثقة البعيدة، وأنه

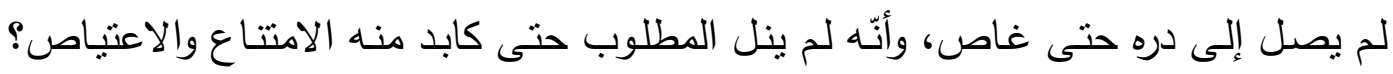

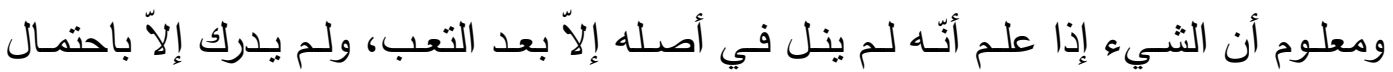

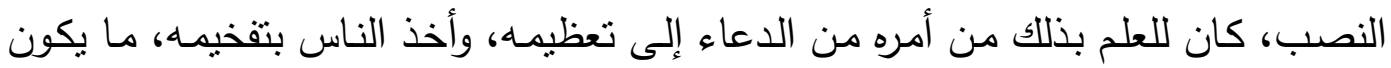

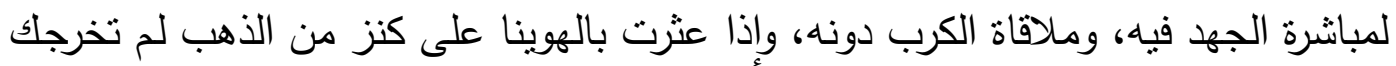

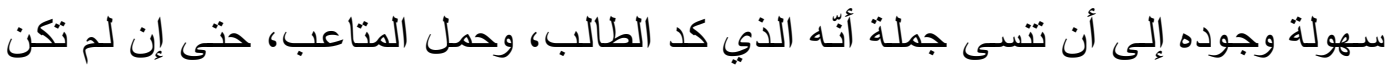

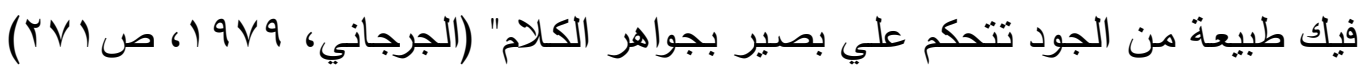
.(Al-Jurjani; 1979; p271)

فوعي القارئ بمكابدة الثاعر في جمع ألفاظه ومعانيه، وبحثه عن التأويلات المناسبة

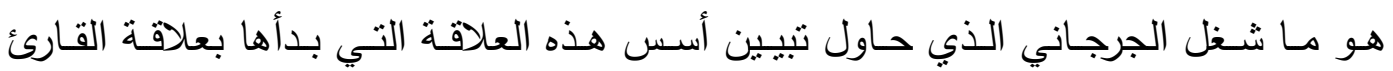

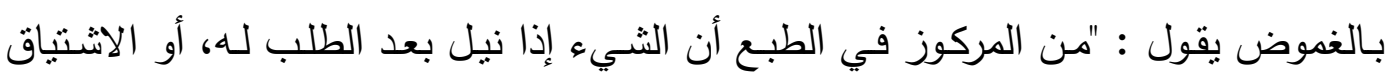

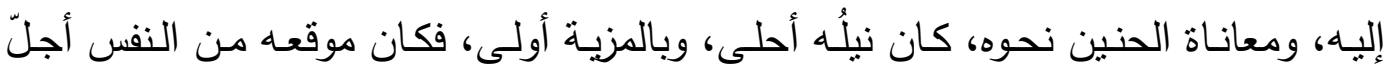

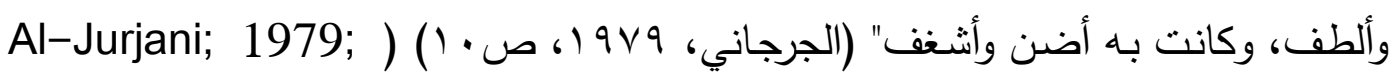

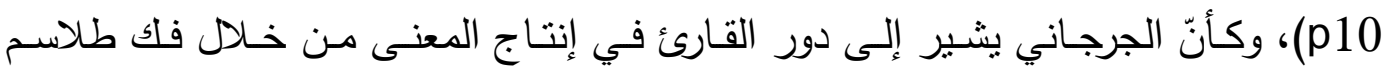

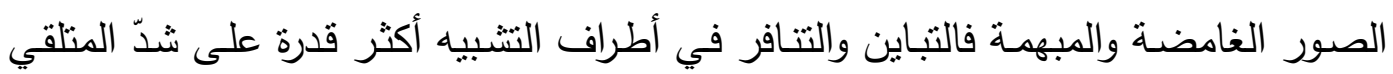
وإثارته واستفزازه لما في هذا التنافر من غموض يحرّك العقل والحسّ معاً، يقول: "كلما كان مكان الثبه بين الثيئين أخفى وأغمض وأبعد من العرف كان الإتيان بكلمة التشبيه أبين 


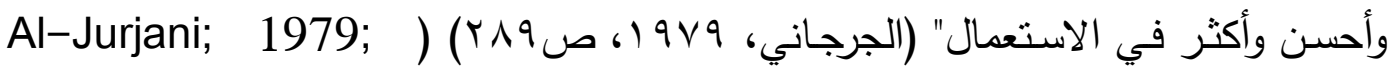
.(p289

أما جون كوهن فقد فسرّ انقطاع الصلة بين القارئ والثعر المعاصر والذي يشكو منه

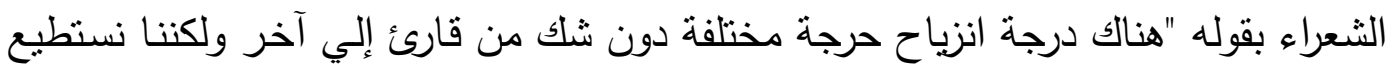

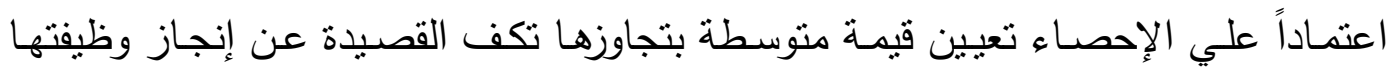

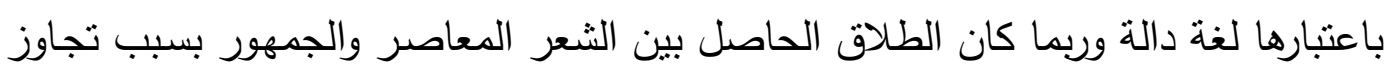

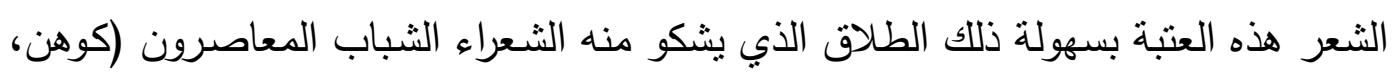

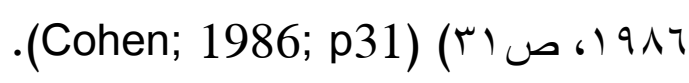
وسمى جون كوهن تلك العلاقة بين القارئ والنص، بـ: "الانفعال الثـعري " (كوهن،

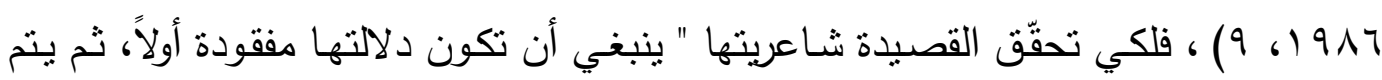

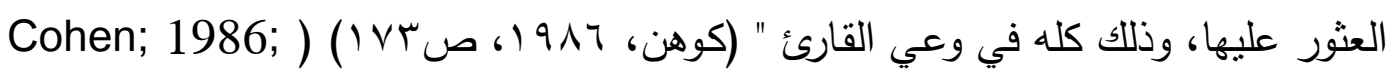
.(p173

وقد أكّد كوهن على الوظيفة التوصيلية للخطاب الثعري و في هذا يقول :"إن الثّعر شأنه شأن النثر خطاب يوجها المؤلف إلى القارئ لا يمكن الحديث عن الخطاب إذا لم يكن

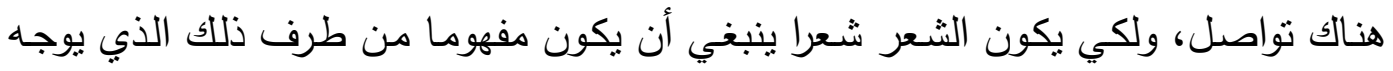

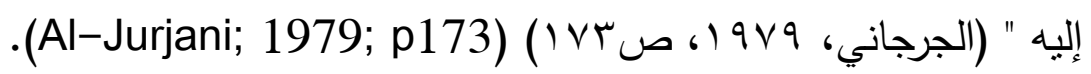

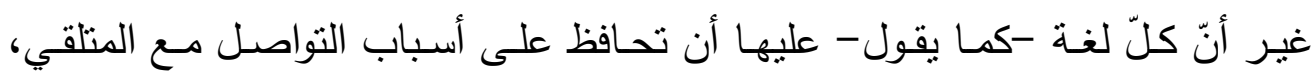

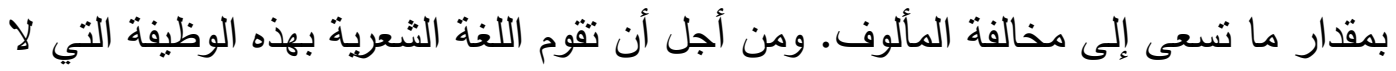

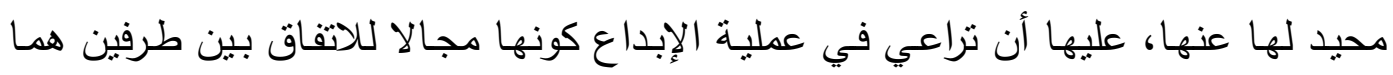

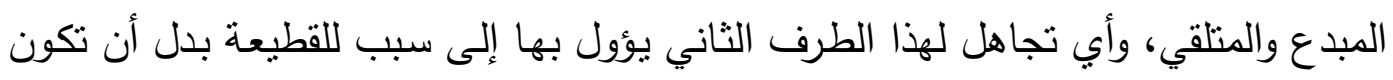
وسيلة للتواصل ( الغذامي، ع 99 1، صلوه) (Al-Ghazhami; 1994; p57).

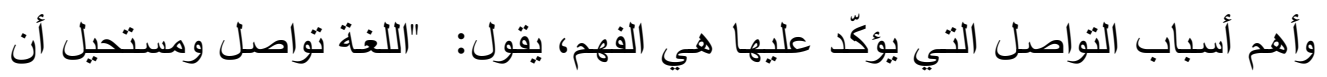

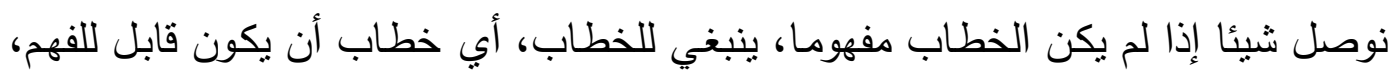

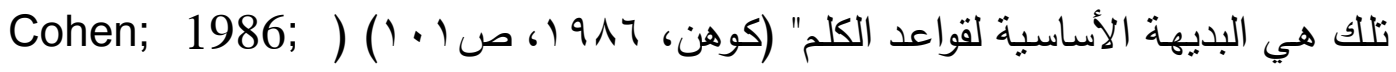

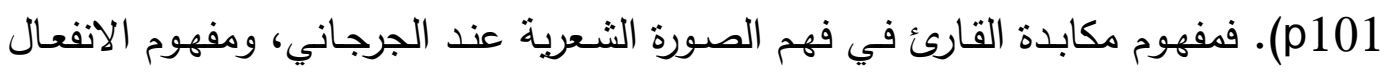

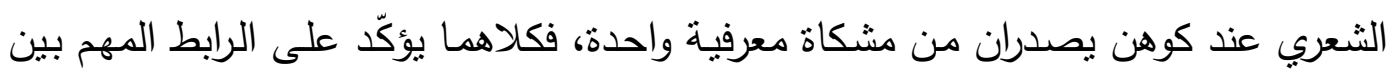
المتلقي والنص عموما والصورة بشكل خاص، تحقيقا للتواصل والتأثير . 


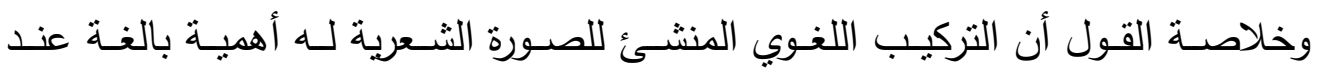

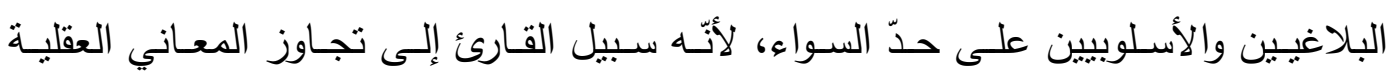

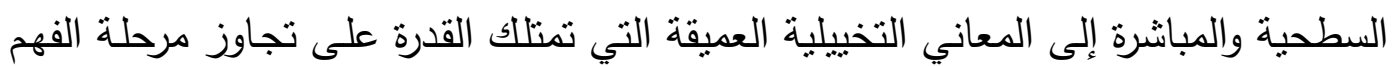

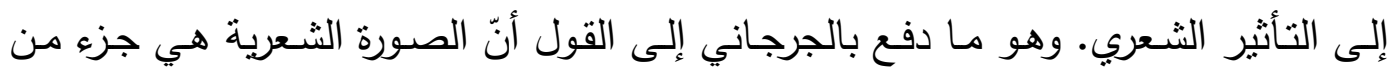

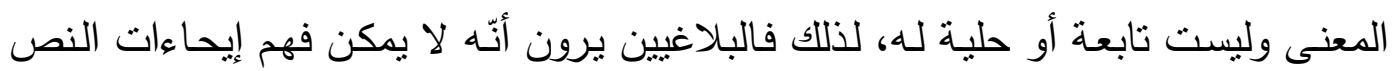

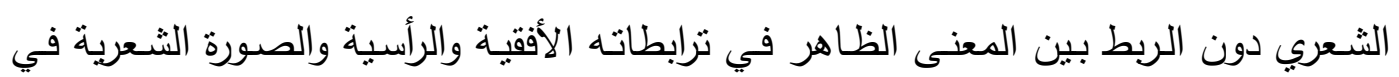
علاقاتها التخيلية والعقلية داخل النظم اللغوي.

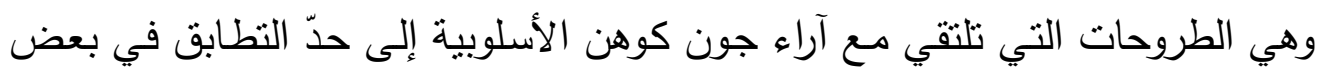

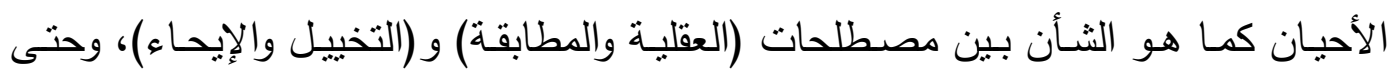

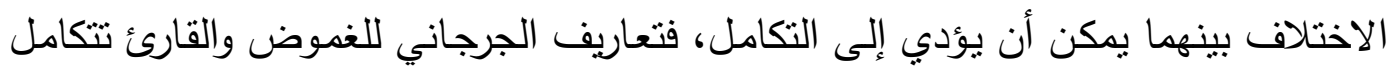

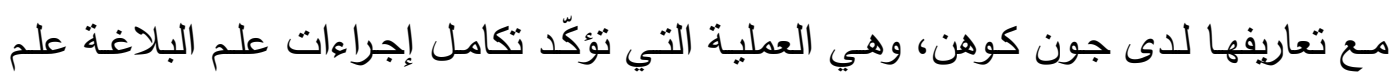

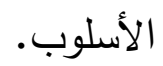
وأفضل ما نختم بـه هذا البحث إثارة الأسئلة ذاتها التي أثنارها محدد الولي في كتابه (الصورة الشعريّة في الخطاب البلاغي والنقدي) والتي تثبت التكامل المعرفي بين البلاغة دأنة

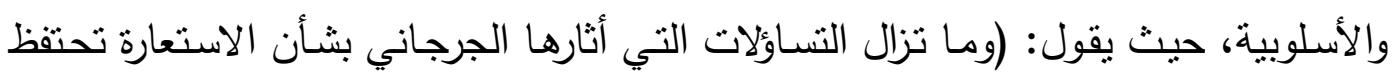

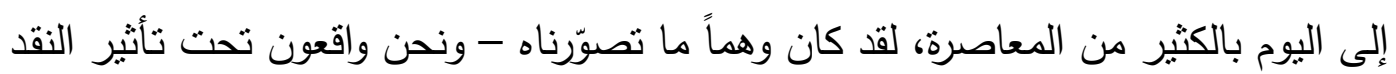

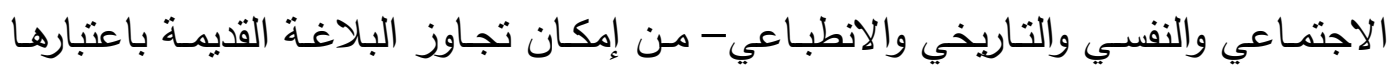

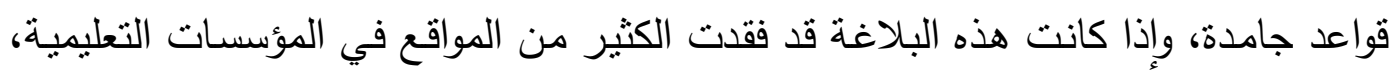

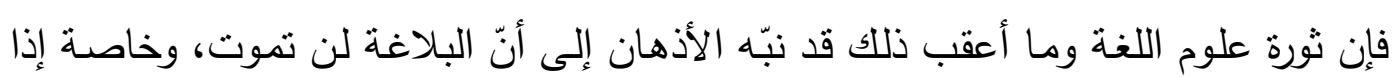

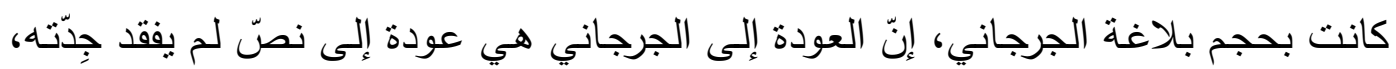

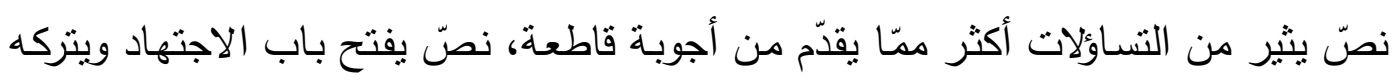
كذنلك). فلا يمكن أن نتجاوز هذا الموروث البلاغي الزاخر بالطروحات النظرية والتطبيقية حول

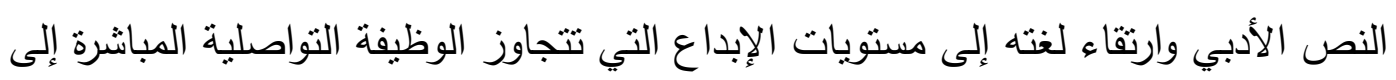

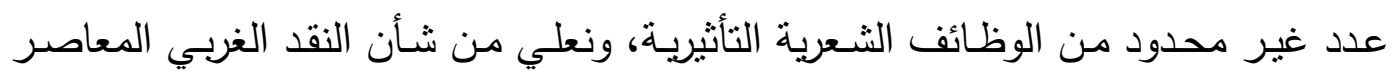

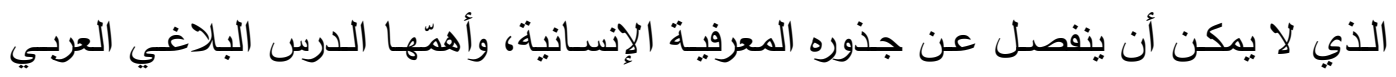
القديم. 
1. ابن منظور، أبو الفضل جمال الدين محمد بن مكرم بن علي الأنصاري الرويفعي الإفريقي: (د،ت)،

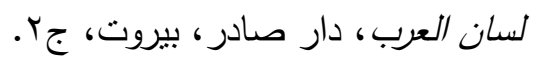

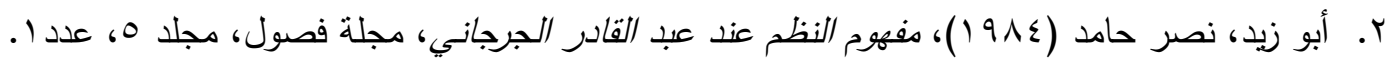

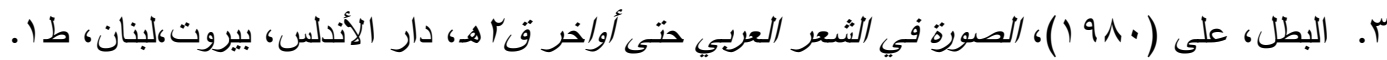

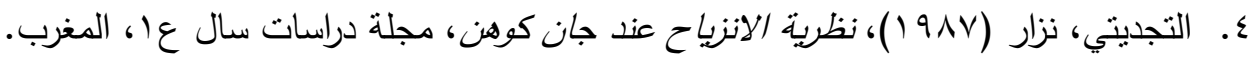

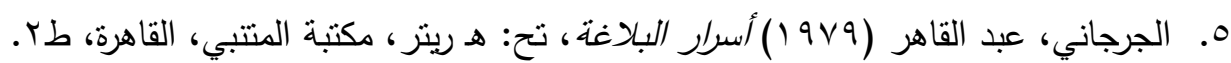

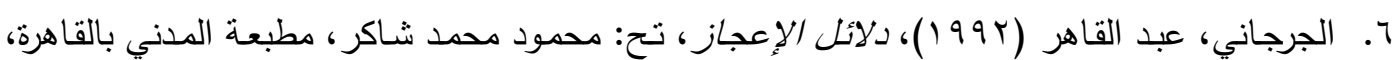

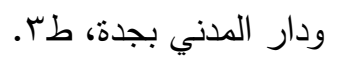

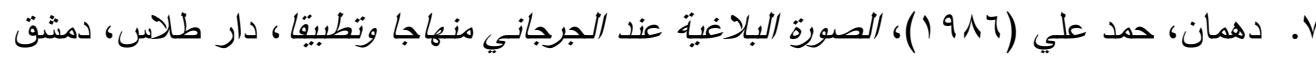

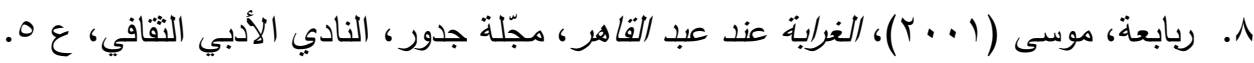

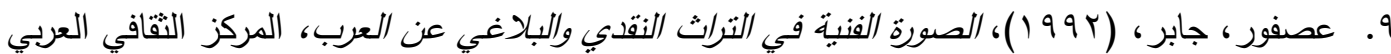

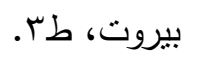

• (. العمري، محمد (999 (1)، البلاغة العربية، الأصول والامتدادات، دار أفريقيا الثرق للنشر ، المغرب.

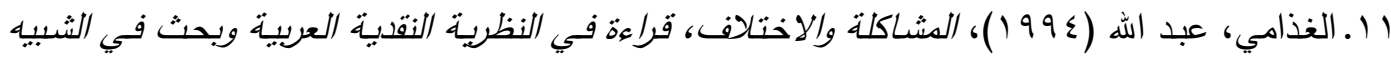

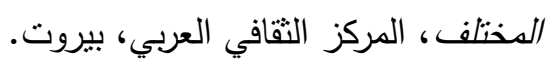

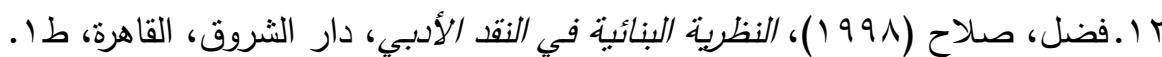

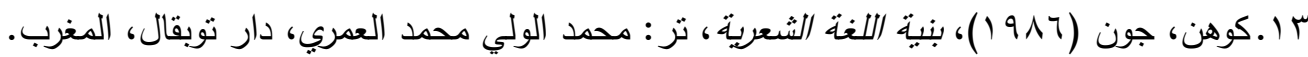

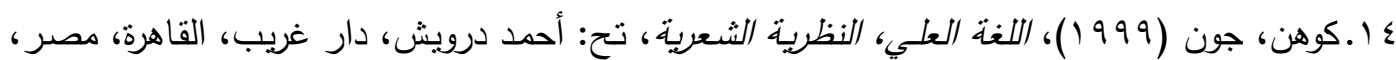
10 هلال، محمد غنيمي (9VY (1)، النقد الأدبي الحديث، دار الثقافة ودار العودة، بيروت.

\section{Sources and references:}

1 Abu Zaid, Nasr Hamid (1984), The Concept of Systems by Abdul Qadir AlJurjani, Fasoul Magazine, Volume 5, No. 1

2 Al-Batal, Ali (1980), the image in Arabic poetry until the late 2nd century AH, Dar Al-Andalus, Beirut, Lebanon, 1st edition.

3 Al-Ghazhami, Abdullah (1994), Problem and Difficulty, Reading in Arab Critical Theory and Research in Different Similarities, Arab Cultural Center, Beirut.

4 Al-Jurjani, Abd al-Qaher (1992), Evidence of Miracles, An Inquiry: Mahmoud Muhammad Shaker, Al-Madani Press in Cairo, and Dar Al-Madani, Jeddah, 3rd Edition.

5 Al-Jurjani, Abd al-Qaher (1979) Asrar al-Balagha, Achievement: H. Ritter, AlMutanabi Library, Cairo, 2nd edition.

6 Al-Omari, Mohamed (1999), Arabic Rhetoric, Origins and Extensions, East Africa Publishing House, Morocco.

7 Al-Tajditi, Nizar (1987), the theory of displacement of Jean Cohen, Journal of Sal Studies I, Morocco. 
8 Asfour, Jaber, (1992), the artistic image in the critical and rhetorical heritage of the Arabs, the Arab Cultural Center Beirut, 3rd floor.

9 Cohen, John (1986), The Structure of Poetic Language, translation: Muhammad al-Wali Muhammad al-Omari, Dar Toubkal, Morocco.

10 Cohen, John (1999), The Most High Language, Poetic Theory, translation: Ahmed Darwish, Dar Gharib, Cairo, Egypt, 4th floor.

11 Dahman, Hamad Ali (1986), The rhetorical picture at Al-Jarjani curriculum and application, Dar Tlass, Damascus

12 Fadl, Salah (1998), Constructivist theory in literary criticism, Dar Al-Shorouk, Cairo, i 1.

13 Hilal, Muhammad Ghanimi (1973), Modern Literary Criticism, Dar AlThaqafa and Dar al-Awda, Beirut.

14 Ibn Manzoor, Abu Al-Fadl Jamal Al-Din Muhammad Bin Makram Bin Ali AlAnsari Al-Ruwa'afi Al-Afriki: (w, d), Lisan Al-Arab, Dar Sader, Beirut, part 2.

15 Rababa, Musa (2001), Abd al-Qaher's Strangeness, Jaddur Journal, Literary Cultural Club, p. 5. 